\title{
Analysis of Factors Affecting the Adoption of Health Technologies: Modification of the UTAUT2 model
}

\author{
Aref Shayganmehr ${ }^{1}$, Gholamreza Malekzadeh $^{{ }^{*}}$, Mariusz Trojanowski ${ }^{2}$ \\ 1. Faculty of Economic \& Administrative Sciences (FEAS), Ferdowsi University of Mashhad (FUM), Mashhad, Iran \\ 2. Warsaw University, Warsaw, Poland
}

Received: 14 Decembery 2020

Accepted for publication: 13 February 2021

[EPub a head of print-23 February 2021]

Payesh: 2021; 20 (1):31-47

\begin{abstract}
Objective (s): In a threatening situation such as Covid-19 Pandemic, E-health is more effective in providing public health, including prevention, monitoring, diagnosis, prioritization, treatment and follow-up patients. Regardless of E-health potential benefits, implementation and adaptation barriers is expected. In this regarding, it is essential to study the factors influencing EHCR adoption. Therefore, this study aimed to investigate the factors affecting the adoption of E-Health.

Methods: In this research, the mixt method approach and exploratory design - typology creation model have been used. After conducting semi-structured interviews and a focus discussion group among physicians, specialists, health experts and CEOs, a research model was developed and tested one a sample of 417 physicians in an online survey. Structural Equation Modeling (SEM) has also been used to analyze the data and test the research hypotheses.

Results: Trust and confidentiality, waiting time, authority, health provider-patient relationship are influencing factors that affect adoption of E-health factor. Five other factors were also found that were similar to the UTAUT2 model: performance expectancy, effort expectancy or ease of use, facilities, price value, habit. All hypotheses were significant because the absolute value of the significant number obtained from the t statistic in all hypotheses was higher than 1.96 , with a 0.84 effect rate.

Conclusion: The findings from this study help to understand the factors influencing behavioral tendency in using E-Health. Theoretical findings, development, and validation in this dissertation provide a framework that includes the factors influencing the adoption of health technology, theoretical foundations for designing and selecting health technology in future health care before they enter the market, or solving the problems of their acceptance implementation.
\end{abstract}

Key Words: E-Health, adoption, mixed methods approach, UTAUT2

\footnotetext{
* Corresponding author: Ferdowsi University of Mashhad (FUM), Mashhad, Iran

E-mail: malekzadeh@um.ac.ir
} 


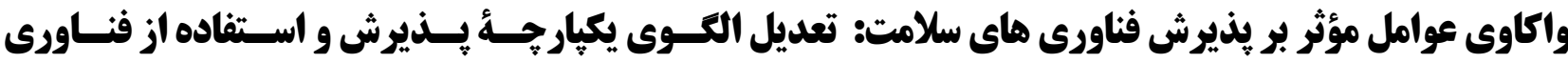

\author{
عارف شايعان مهر' ، غلامرضا ملك زاده '، ماريوس تروجانوسكى \\ I. دانشكده علوم ادارى و اقتصادى، دانشخاه فردوسى مشهد، مشهد، ايران

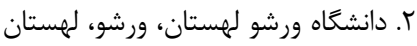

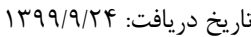

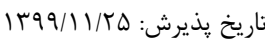

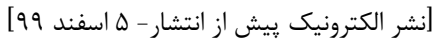

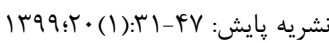

مقدمه: با بروز پاندمى كويد-9 ا توجه بيشترى به استفاده از فناورى سلامت معطوف شده است، ولى عدم توجه به عوامل موثر بر پذيرش و تطابق

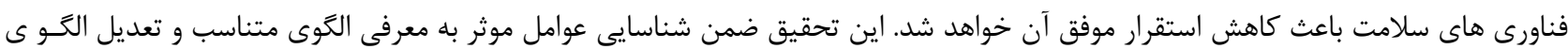

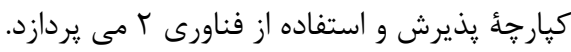

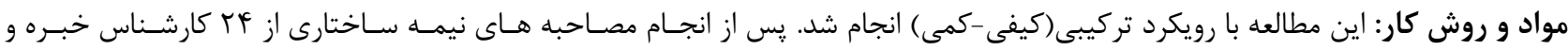

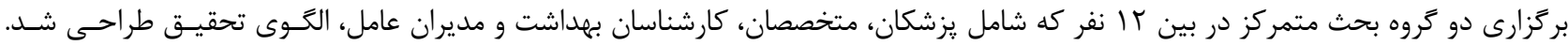

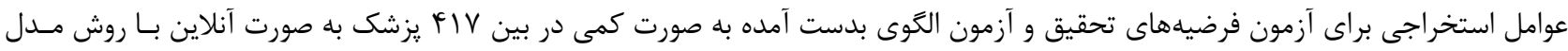

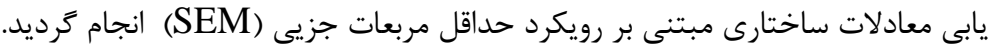

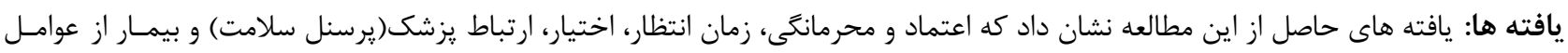

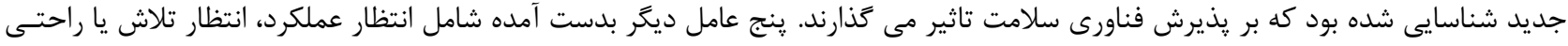

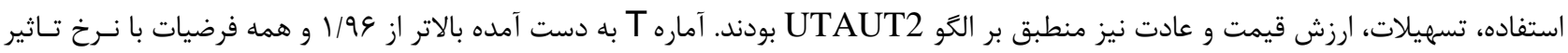

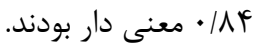
نتيجه كيرى: توجه به نتايج بدست آمده از اين مطالعه، الكَى ماحصل ابزار مناسبى براى سنجش يذيرش فناورى سلامت است.

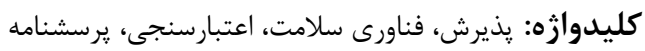


وابسته به عوامل اجتماعى و هنجارهاى فردى است كه نهايتـا باعثث

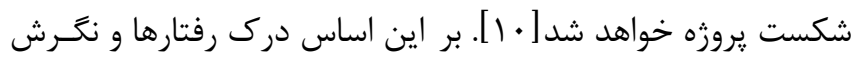

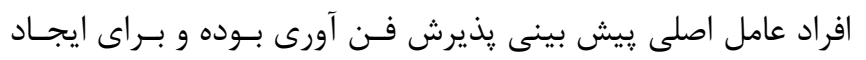

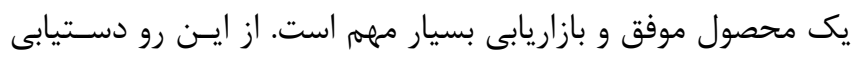

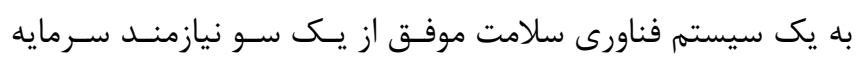

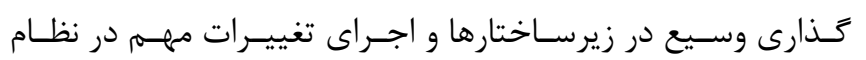

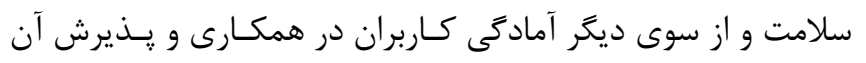

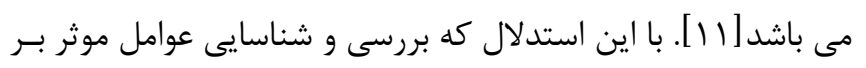

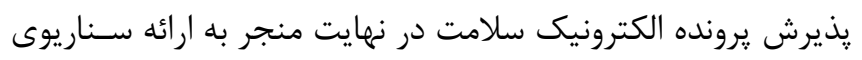

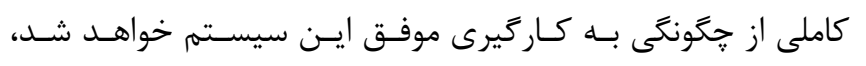

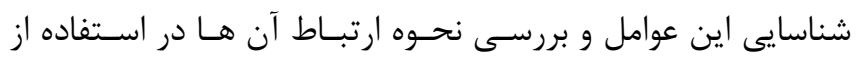

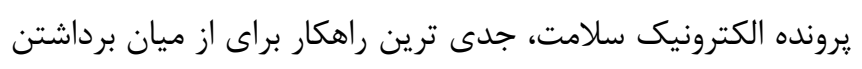

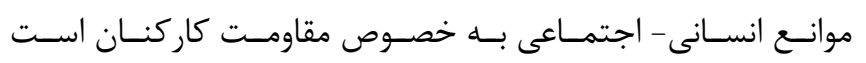

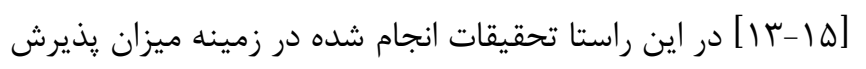

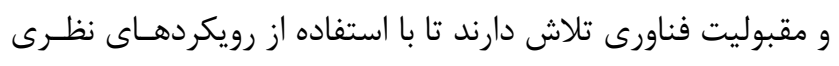

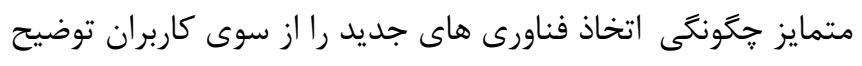

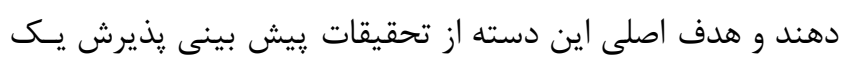

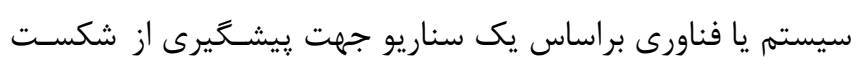

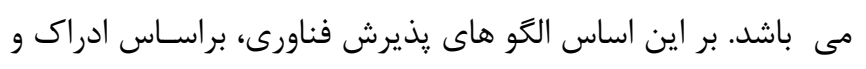

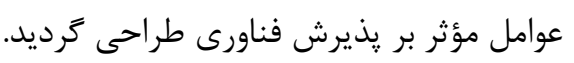

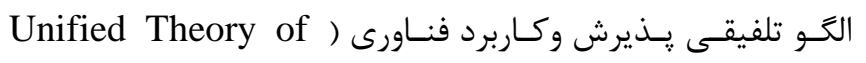
، UTAUT2 (Acceptance and Use of Technology2

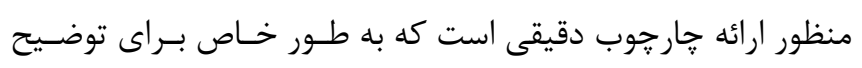

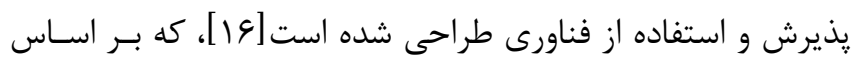

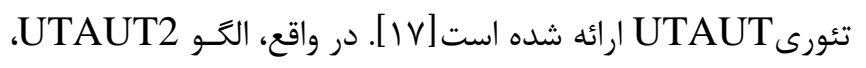

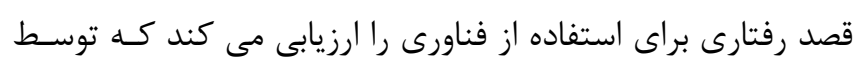

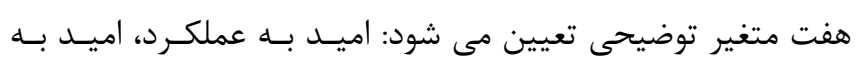

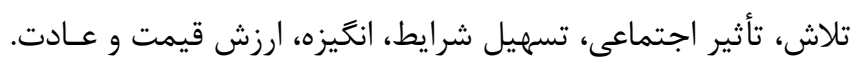

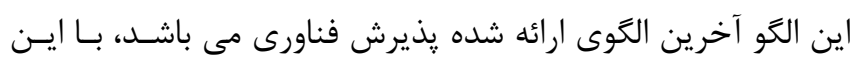

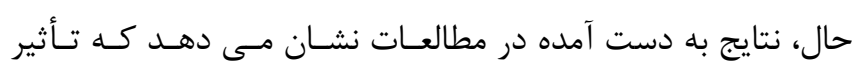

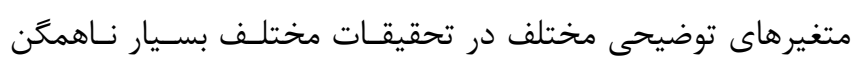

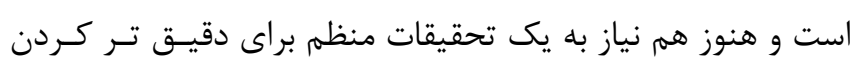

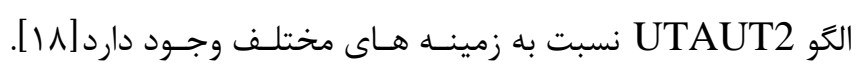

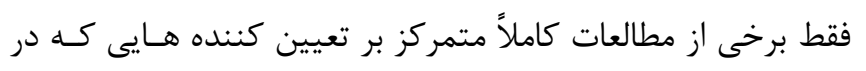

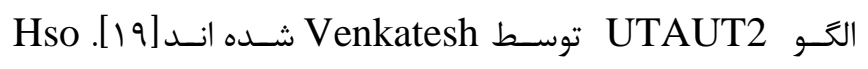

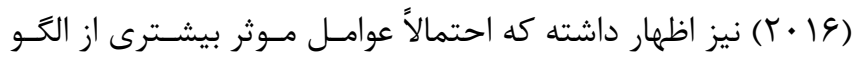

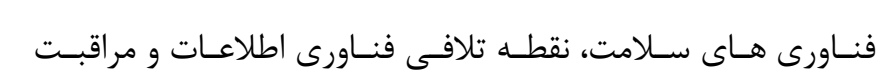

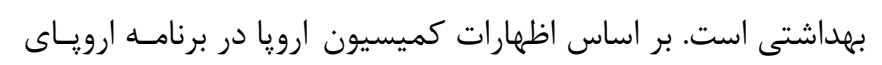

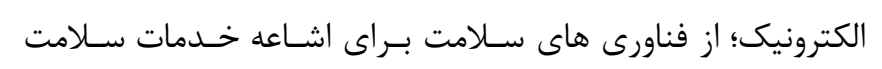

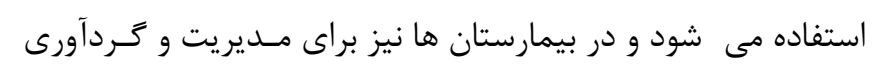

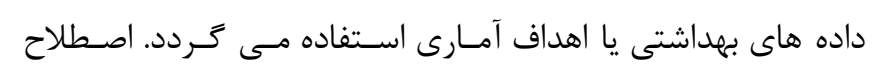

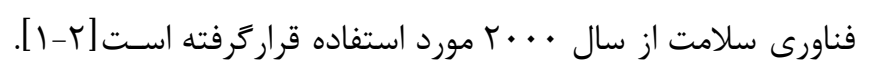

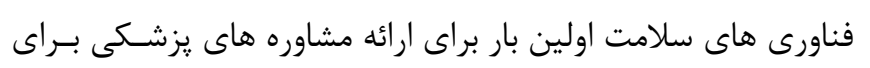

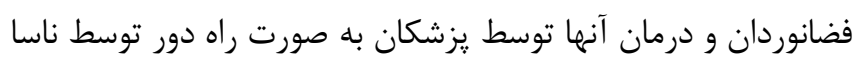

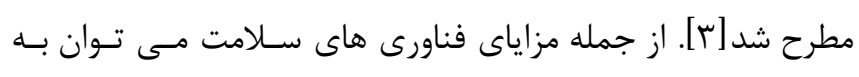

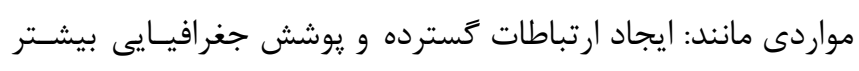

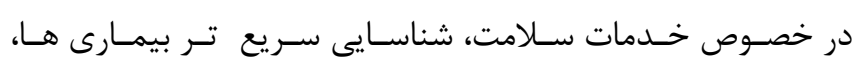

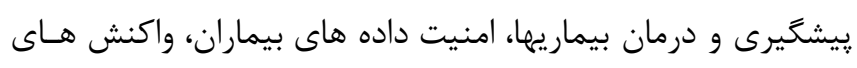

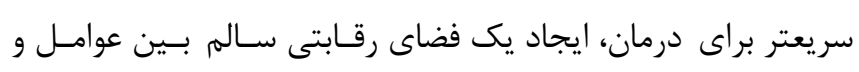

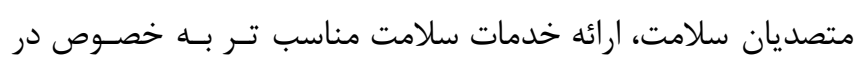

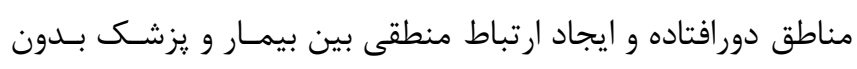

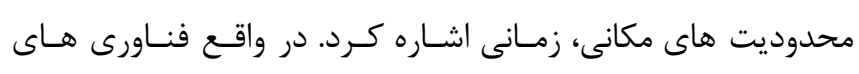

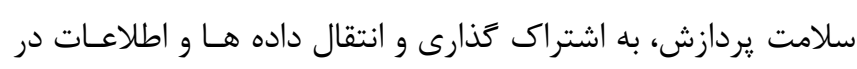

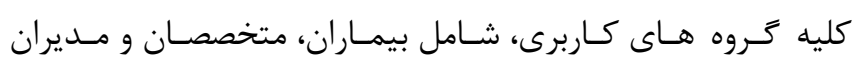

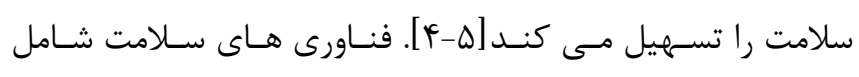

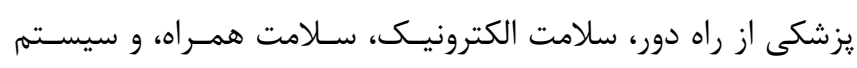

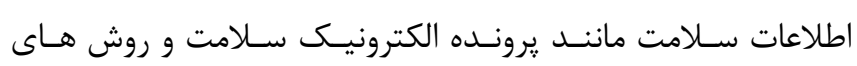
درمانى مجازى است.

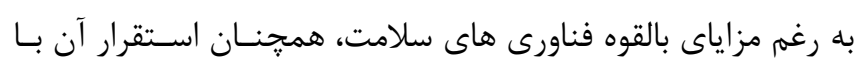

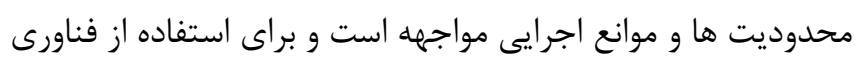

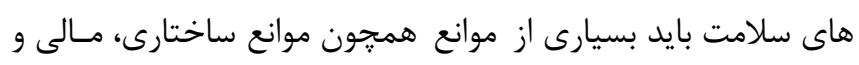

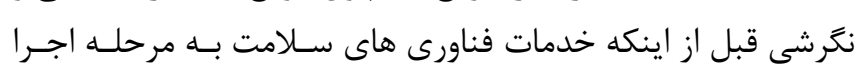

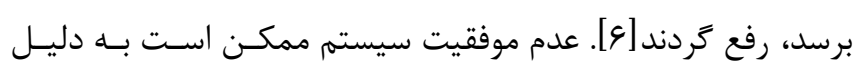

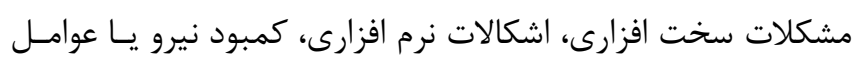

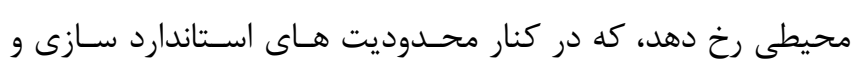

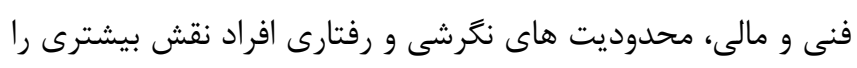

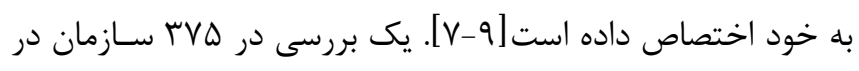

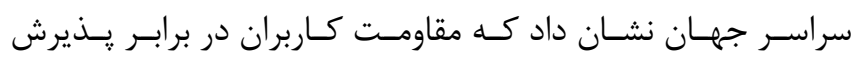

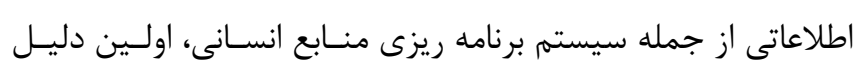

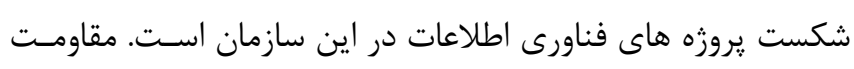

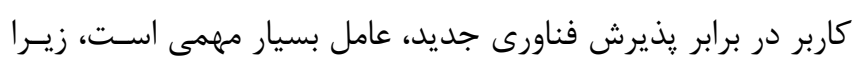


يزشكان، كارشناسـان بهداشـتى، روانشـناس اسـتفاده شـــ عوامـل

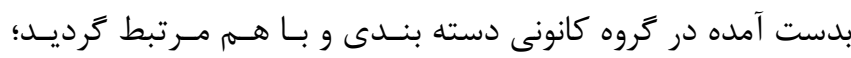

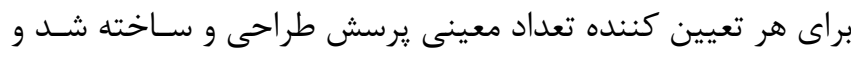

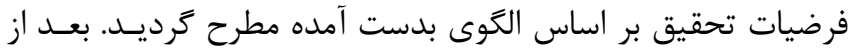

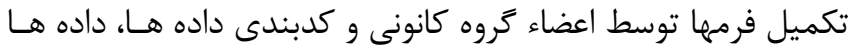

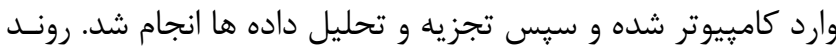
تحليل زمانى شروع مى شود كه تحليلكر الكَوهـاى معنـا و مضـامين مناسب را در نظر بخيرد. اين تجزيه و تحليل شامل جابجايى مـداوم

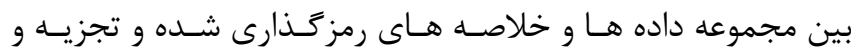

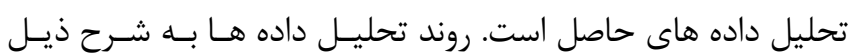

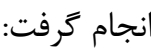
- محقق مصاحبه ها و مشاهدات را تبديل به متـون كتبسى نمـوده و

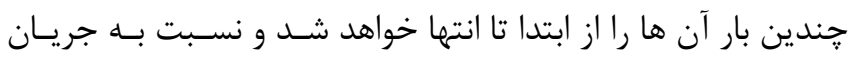
كلى در حال وقوع شناخت كسب ترديد. ـكل مصاحبه ها و مشاهده ها به عنوان واحد تحليل لحـاظ ترديـد.

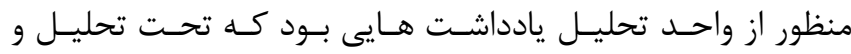

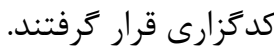

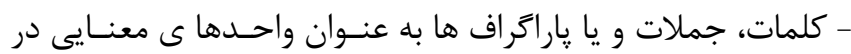
نظر كرفته شدند. واحدهاى معنايى مجموعه اي از كلمات و جملات

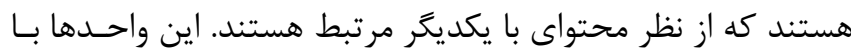
توجه به محتوا و مفادشان جمع بندى شده و در كنار يكـديكر قـرار

$$
\text { مى كرفتند. }
$$

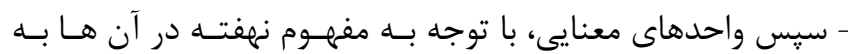
سطح انتزاع و مفهوم يردازى رسيده و توسط كدها نام كذارى شدند. - كدها از نظر تشابهات و تفاوت هايشان با يك ديكر مقايسه شـدند

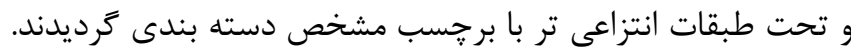

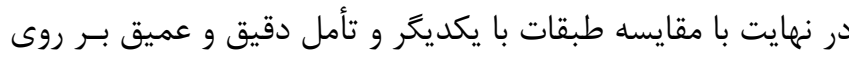

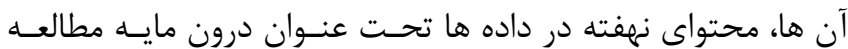

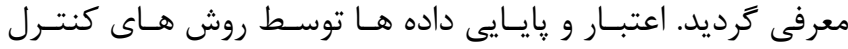

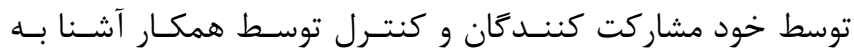
تحقيق كيفى سنجيده شد. در كنتـرل توسـط مشـاركت كنـــــان،

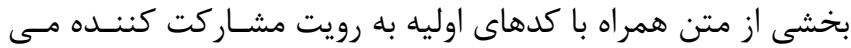

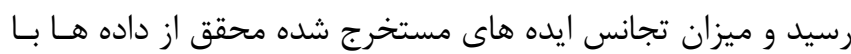

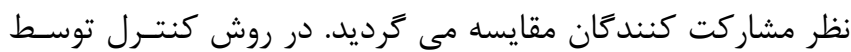
همكار، مفاهيم و طبقات ايجاد شده از داده ها به همكاران آشــنا بـهـ

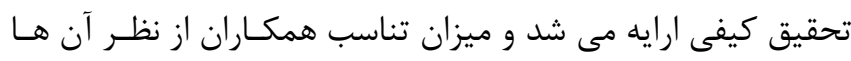

يذيرش موجود وجود دارد كه ناشى از تفاوت هاى فرهنحسى اسـت و

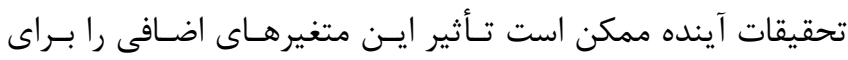

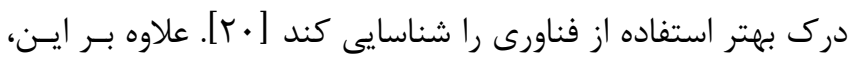

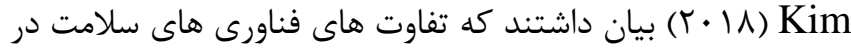

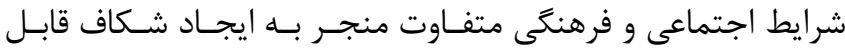
توجهى در درك نسبت به هنين تغييرات فنـاورى در محسيط هـاى فئاى

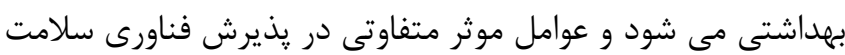

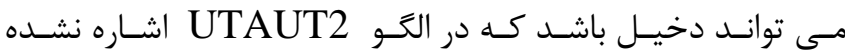

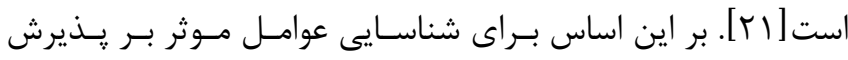

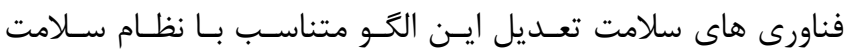

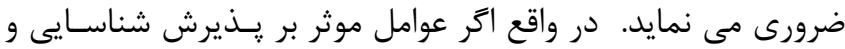

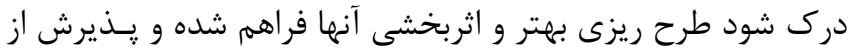

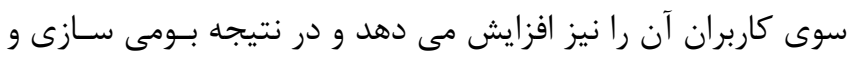

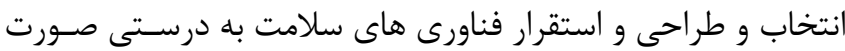
كرفته و از هدر رفت منابع نيز جلوكيرى خواهد شد. لذا با توجه بــهـ

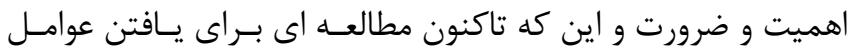
موثر بر روى يذيرش فناورى سلامت در نظام سـلامت ايـران انجـام

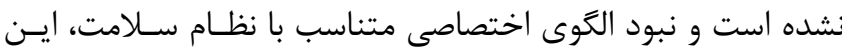

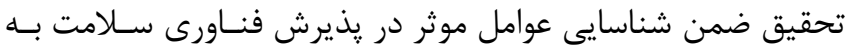

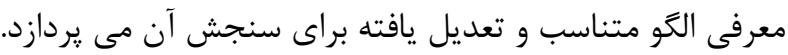

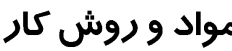

راهبرد تحقيـق حاضـر روش آميختـه (Mixed Method) اســـ مارد

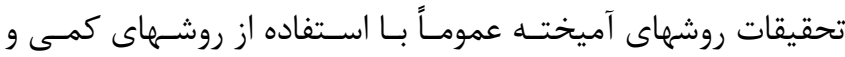

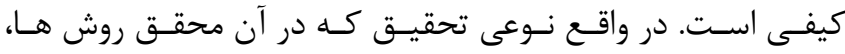

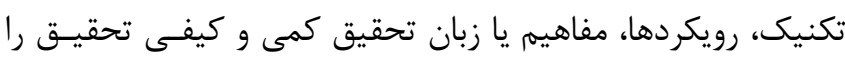

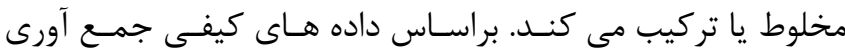

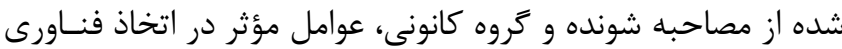

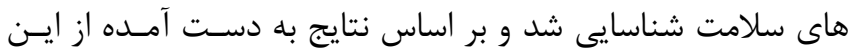
مرحله، فرضيه هاى تحقيق شكل كرفت و منجر به اضافه شدن سازه

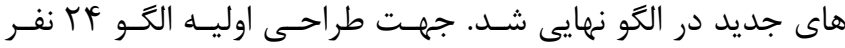

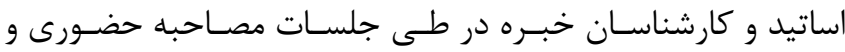

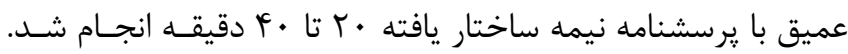
بعد از تكميل مصاحبه و استخراج مضمون ها جهت تاييـد مضـمون

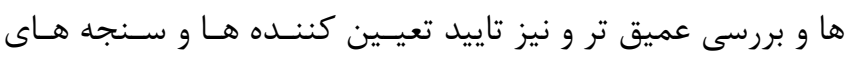

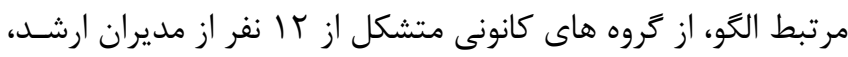


99 9 • درصد و براى حيطه واضح بودن معـادل 91/D درصـد بدسـت

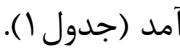
اجراى اوليه آزمون: در تحليل مسير PLS براى مفههم سـازى يـك

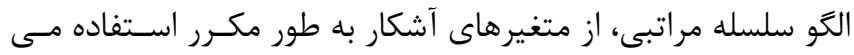
شود. بدين ترتيب، يك متغير ينهان مرتبه بالاتر مى تواند به وسـيله

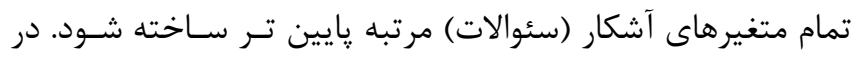

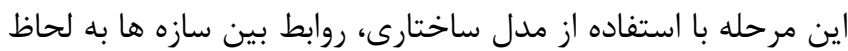

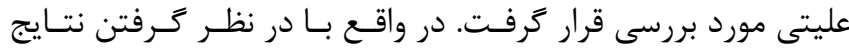

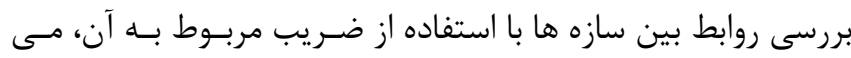

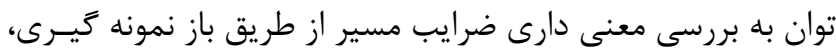

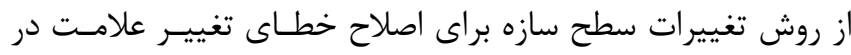

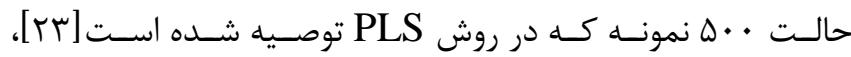
استفاده گرديد. جهت سنجش متغير يذيرش فناورى سلامت در اين تحقيق نه عامل متغير با و\& گويه در قالب طيف ليكرت و در ساطح سنجش رتبه اى استفاد شد.

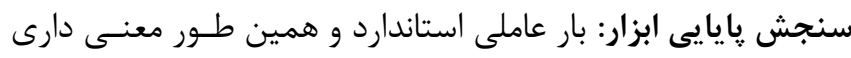

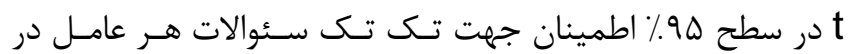

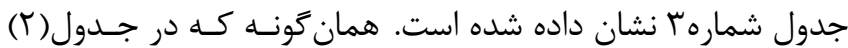
مشاهده مى گردد، بارهاى عاملى براى متغيرهاى تحقيـق بـالاى ها •

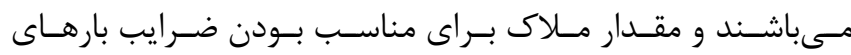

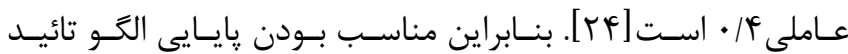

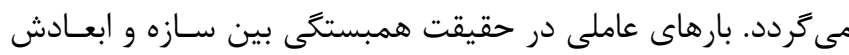

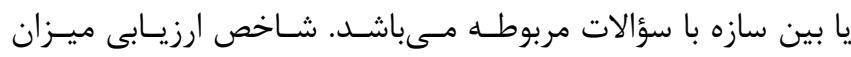

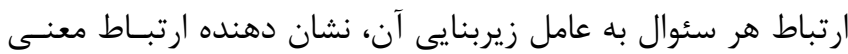

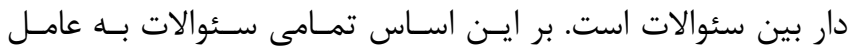

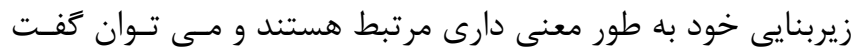

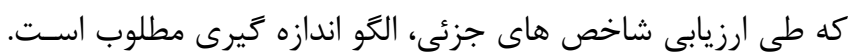
در اين راستا سه نوع شاخص بررسى يايايى شامل همخَـونى درونسى،

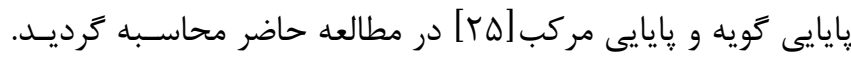

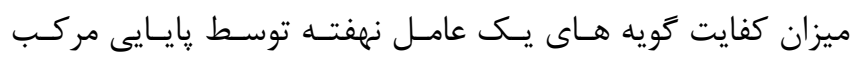

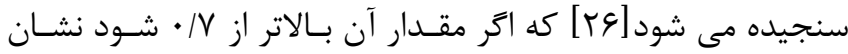
دهنده پايايى درونى مناسب است. يايايى مركب معيار بهترى نسبت

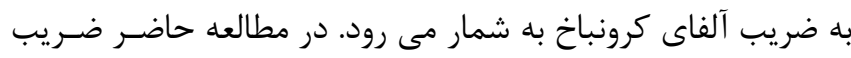

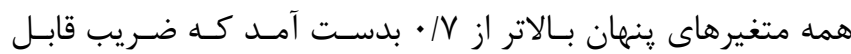

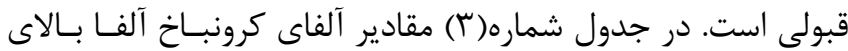

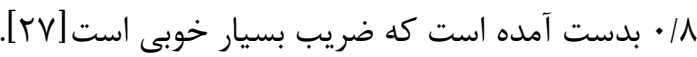

كنترل مى گرديد و در صورت وجود اختلاف نظـر بـين همكـاران و محقق، مجدداً تحليل و مفهوم يردازى داده ها توسط محقق صـورت

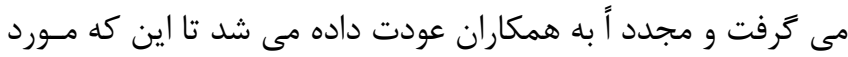
تأييد و اجماع نظر آن ها قرار مى گرفتند. در اين مطالعه در ادامه از

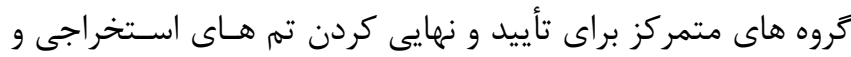
توسعه الكو استفاده شده است. مرحله دوم نمونه تحقيق حاضر از نوع احتمالى و تصادفى بود. قصد اساسى در اين مرحله ارزيابى و سنجش مقياس هاى بدست آمـده و

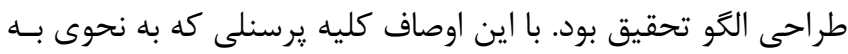

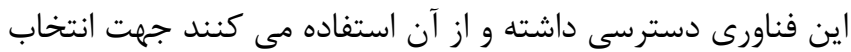

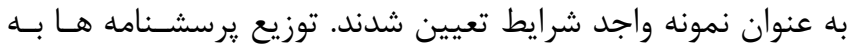
صورت برخط در سطح ايران بود. وزارت بهداشت درمـان و آمـوزش

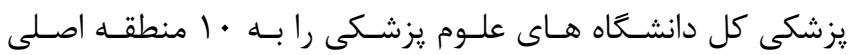
تقسيم نموده است كه نمونه ها از بين اين · ل قطب اصـلى انتخــاب شدند. در اين مرحله حجم نمونه با استفاده از فرمول كوكران تعيين

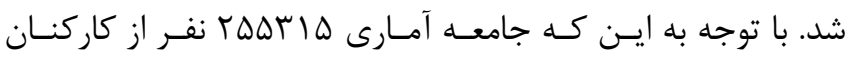

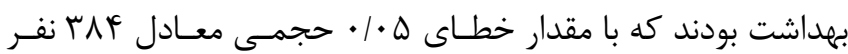

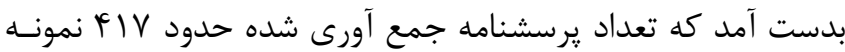

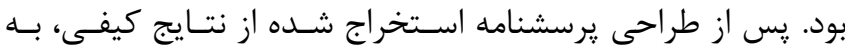

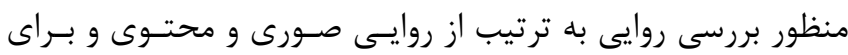

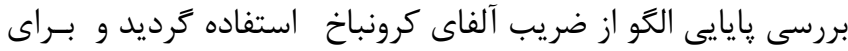
آزمون فرضيات از طرح هاى همبستخى و به صـورت خـاص تحليـل

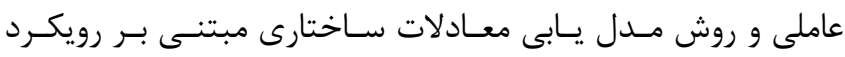
حداقل مربعات جزيى (SEM) استفاده شد. روش حــداقل مربعـات جزيى معمولا براى توضيح واريانس الكو تحقيـق و شناسـايى سـازه هاى كليدى استفاده مى شود و اين روش ريش بيش بينى مدار بوده و در

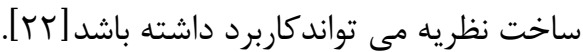

يافتهها

يس از جمع آورى يرسشنامه هاى مـرتبط بـا هـر تعيـين كنـــده از

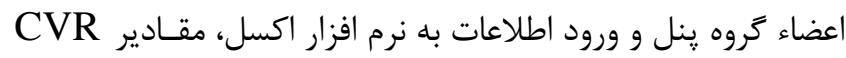
براى هر كدام از گويه ها و نيز براى كل يرسشنامه محاسبه شد كه كل يرسشنامه بعد از حذف VVR

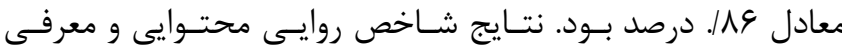

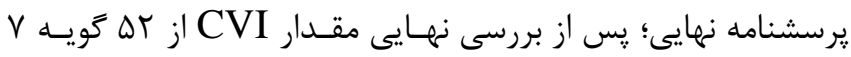

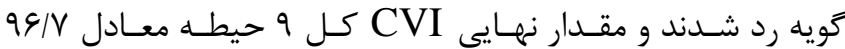
درصد محاسبه شد. مقدار CVI بـراى حيطـه سـاده بـودن معـادل 


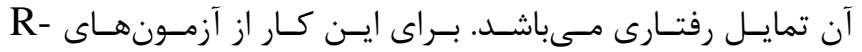

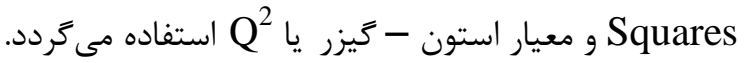

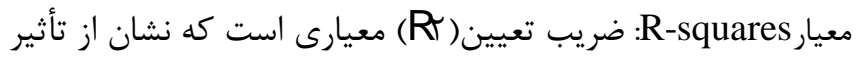
يك متغير مستقل يا برونزا بر يك متغير درونزا(وابسته) دارد. ايـن إنـ

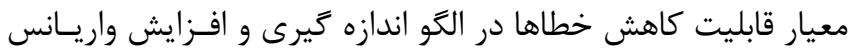

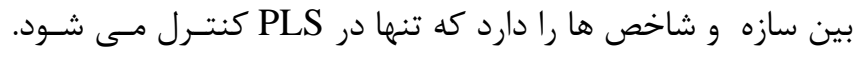

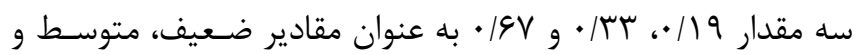

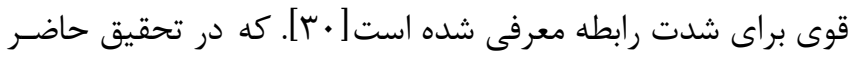

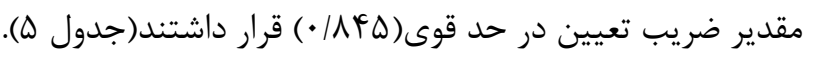

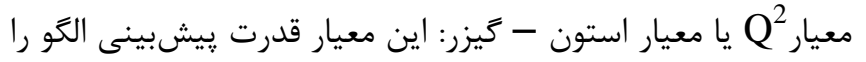

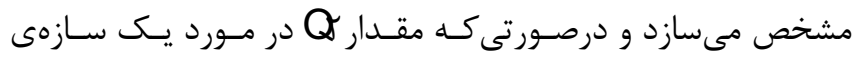

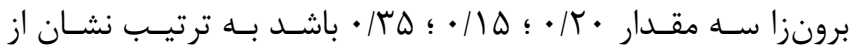

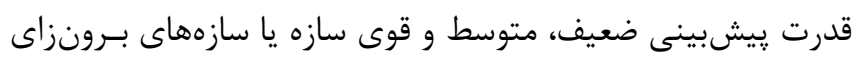

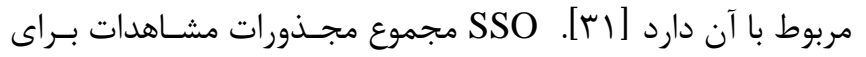
هر گروه يا بلوك را نشان مى دهد. SSE مجموع مجـذور خطاهـاى

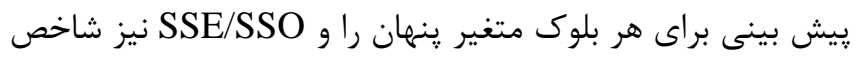

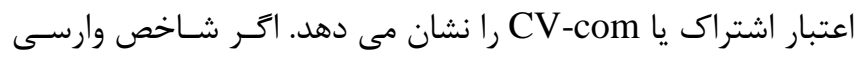

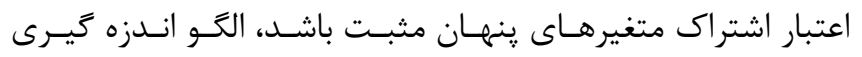

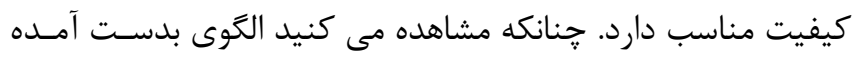

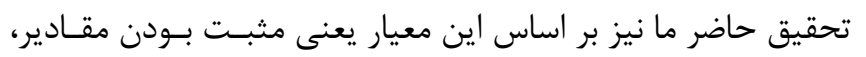

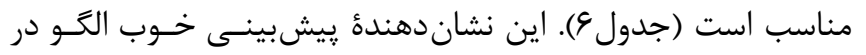

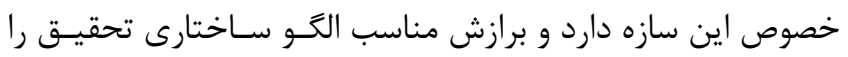

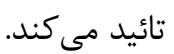

برازش الكَ كلى تحقيق يا GoF(شاخص نيكويى برازش GOF)

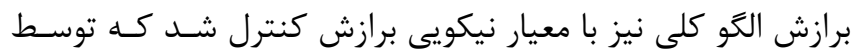

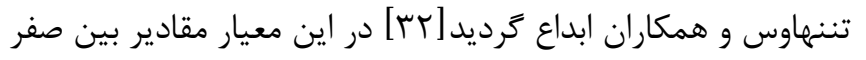

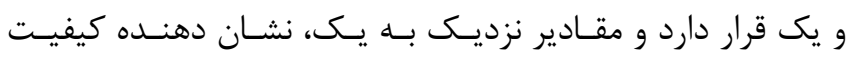

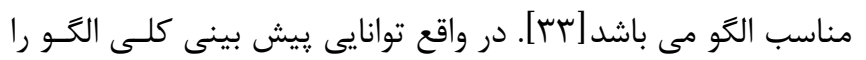

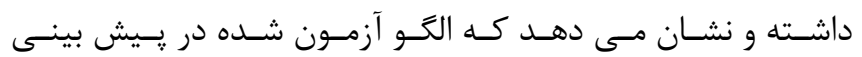

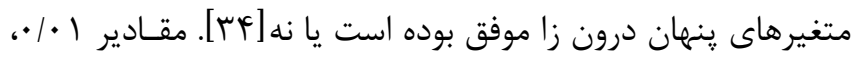

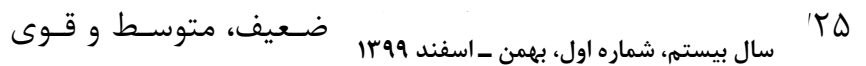

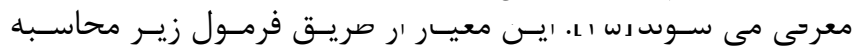
مى تردد.

$\mathrm{GOF}=\sqrt{\text { communalities } \times R-\text { squares }}=0 / 68 * 0.84=. V \Delta$

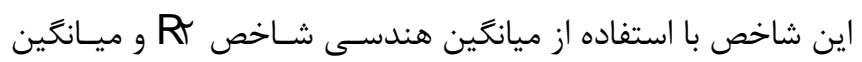

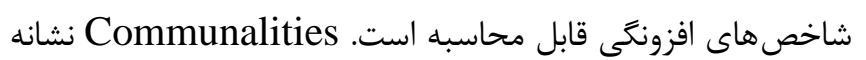

روايى ابزار: روايى همكرا، سنجش ميزان تبيين متغير ينهان توسط

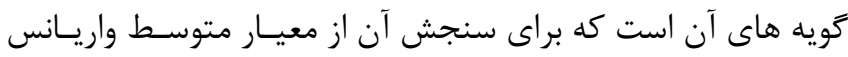

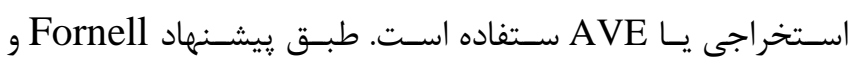
Larcker Magner

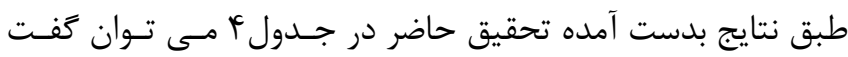

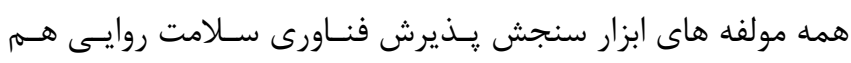

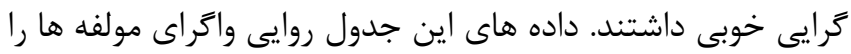

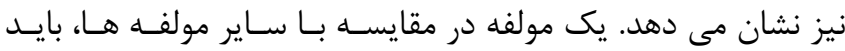

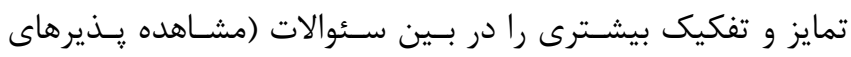
خودش) داشته باشد تا بتوان كَفت مولفه مدنظر داراى روايى بـالايى

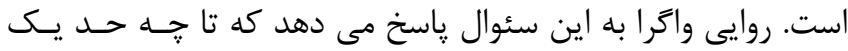

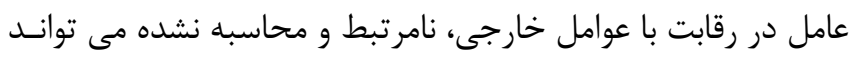

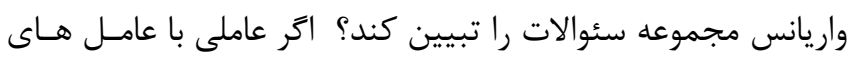

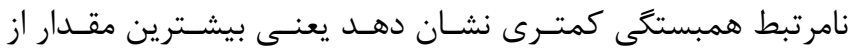

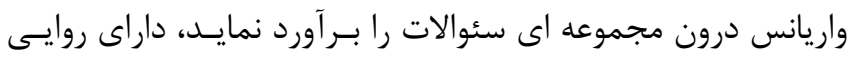

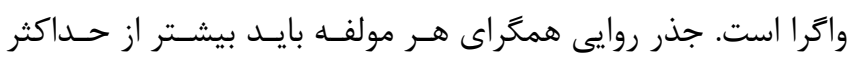

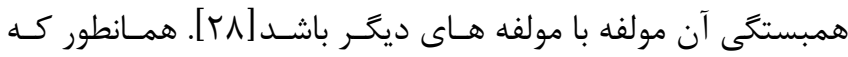

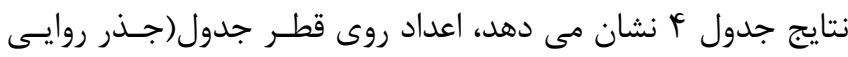

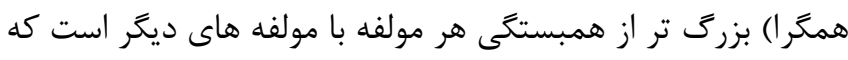

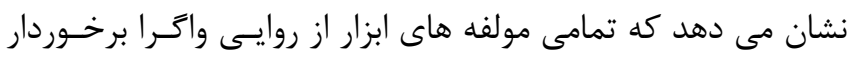
است. (جدول أ. روايى همكرا و روايى واگرا)

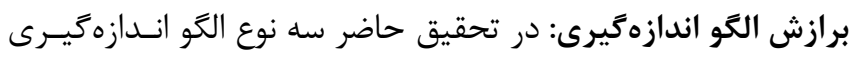

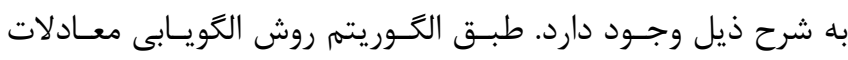

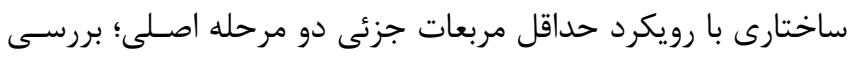

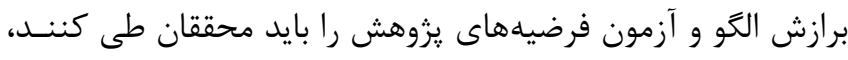

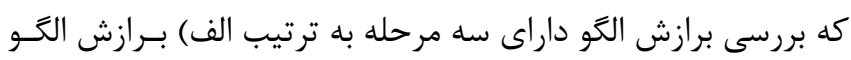

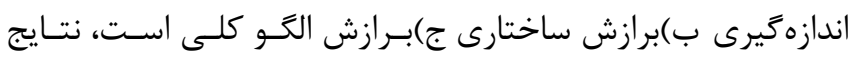

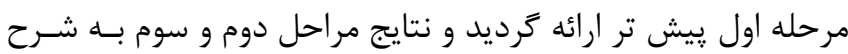

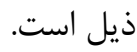
برازش الكَو ساختارى: الكَو ساختارى به بررسى روابط موجـود بـين

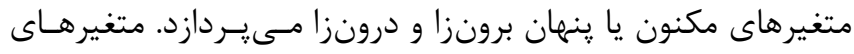

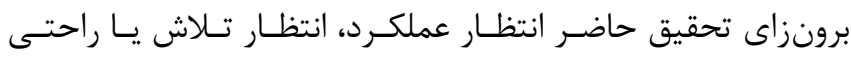

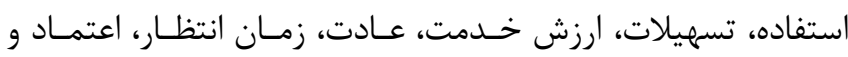
امنيت، اختيار، ارتباط كاربر و بيمار بوده و متغير درونزاى(وابسـتهـ) 
صحت رابطه ها را نشان مى دهد و نه شدت رابطه بين سازه هـا. بـا

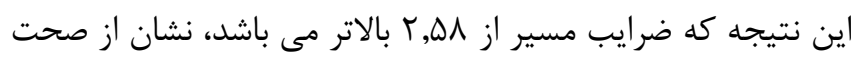

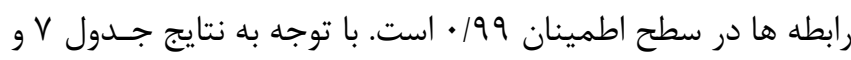
شكل ا از آنجايى كه قدر مطلق عدد معنى دارى حاصل از آمـاره

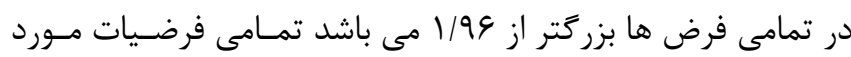

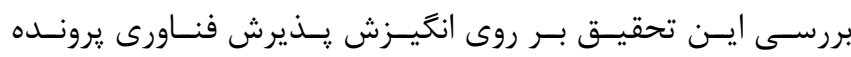

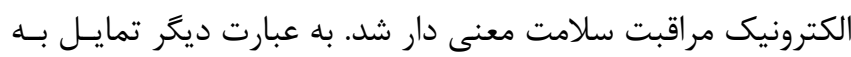
رفتار با انتظار عملكرد، انتظار تلاش يا راحتى اسـتفاده، تسـهيلات،

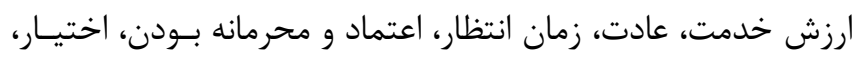

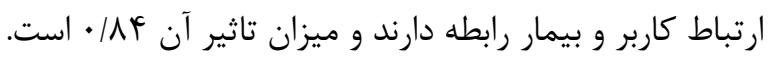

ميانگين مقادير اشتراكى مىباشد و اين مقادير در اين حقيق برابر با

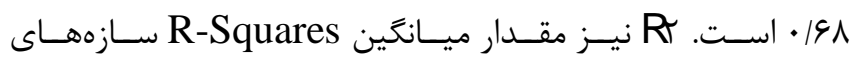

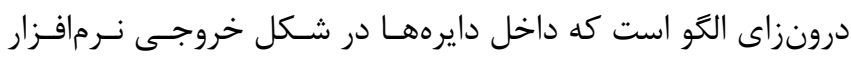

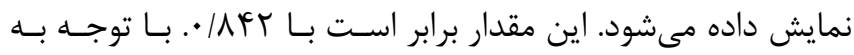

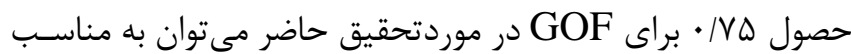

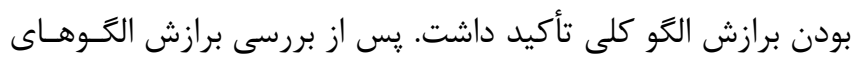

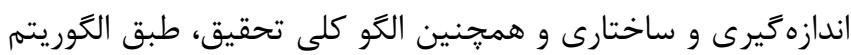

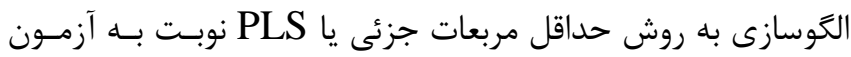

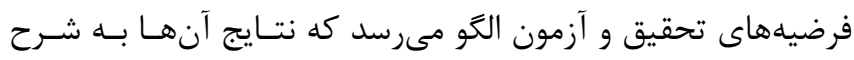

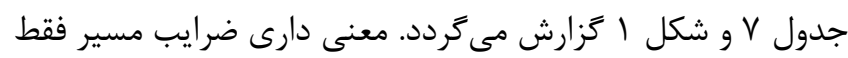

جدول ا: مقدار شاخص روايى محتوا و نسبت روايى محتوا

\begin{tabular}{|c|c|c|c|c|c|c|}
\hline 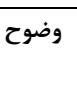 & CVI & 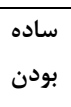 & CVR & فرواييد. خشمند است با علامت ضر بدر، نظر خود رادر مورد در خصوص هركدام از فناورى هاى سلامت مورد اسـتفاده مشــص & فردي & ابعاد \\
\hline 1 & 1 & 1 & 1 & كاربرد اين فناورى سلامت منجر به خدمات بهتر در مراكز سلامت مى شود & 1 & انتظار عملكرد \\
\hline 1 & 1 & 1 & 1 & كاربرد اين فناورى سلامت را مفيد مى دانم & r & \\
\hline 1 & 1 & 1 & 1 & كاربرد اين فناورى سلامت به انجام سريع تر كارها كمك مى كند & r & \\
\hline 1 & $\cdot / 1 \Delta$ & 1 & $\Lambda V / \Delta$ & كاربرد اين فناورى سلامت به افزايش بهره ورى كمك مى كند & r & \\
\hline 1 & 1 & 1 & 1 & يادَّيرى نحوه استفاده از اين فناورى سلامت آسان است & $\Delta$ & انتظـار تـلاش يــا \\
\hline 1 & 1 & 1 & 1 & اين فناورى سلامت واضح و قابل فهمم است & 与 & راحتى استفاده \\
\hline 1 & 1 & 1 & 1 & كسب مهارت در استفاده از اين فناورى سلامت آسان است & $v$ & \\
\hline$\cdot / \mathrm{V} \Delta$ & $\cdot / \Lambda \Delta$ & 1 & $\cdot / v \Delta$ & افراد داراى معلوليت جسمى همم مى توانند از اين فناورى سلامت استفاده كنند & $\wedge$ & \\
\hline 1 & 1 & 1 & 1 & تجهيزات و امكانات لازم براى اين فناورى سلامت در دسترس است & 9 & تسهيل شرايط و \\
\hline 1 & 1 & 1 & 1 & اينترنت براى استفاده از اين فناورى سلامت هميشه و همه جا وجود دارد & 1. & 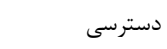 \\
\hline$\cdot / \Lambda \Delta$ & $\cdot / 1 \Delta$ & $\cdot / V \Delta$ & $\cdot / v a$ & اين فناورى سلامت ميتواند خدمات سلامت متناسب با اولويت هاى بهداشتى منطقه ارائه دهد & 11 & \\
\hline 1 & 1 & 1 & 1 & هرموقع در استفاده از اين فناورى سلامت براى من مشكلى يِيش بيايد كسى هست كه به من كمك كند & it & \\
\hline 1 & 1 & 1 & 1 & آموزش هاى لازم براى استفاده از اين فناورى سلامت را ديده ام & ir & \\
\hline$\cdot / \Lambda \Delta$ & $\cdot / 1 \Delta$ & 1 & $\cdot / V \Delta$ & خدمات اين فناورى سلامت در تمامى مناطق حتى مناطق دورافتاده نيز در دسترس است & if & \\
\hline 1 & 1 & 1 & 1 & خدمات اين فناورى سلامت در طول TF ساعت در دسترس است & 10 & \\
\hline$\cdot / \Lambda \Delta$ & $\cdot / 1 \Delta$ & 1 & $\cdot / V \Delta$ & هزينه هاى استفاده از اين فناورى سلامت معقول است & 19 & هزينــه خــدمات \\
\hline 1 & 1 & 1 & 1 & استفاده از اين فناورى سلامت باعث كاهش هزينه هاى سلامت و درمان مى شود & iv & 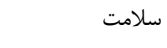 \\
\hline 1 & 1 & 1 & $\cdot / \Lambda \Delta$ & استفاده از اين فناورى سلامت باعث كاهش يرداخت از جيب مردم مى شود & 11 & \\
\hline$\cdot / 1 \Delta$ & 1 & 1 & 1 & حتى اكر هزينه هاى اين فناورى سلامت بالا باشد بازهم ارزش استفاده را دارد & 19 & \\
\hline 1 & 1 & 1 & 1 & به استفاده از اين فناورى سلامت عادت كرده ام & r. & عادت و روزمركى \\
\hline 1 & 1 & 1 & 1 & به اين فناورى سلامت وابسته شده ام و نمى توانم با سيستم قديم كار كنم & rl & \\
\hline 1 & 1 & 1 & 1 & كار با اين فناورى سلامت برايم عادى شده است & rt & \\
\hline 1 & 1 & 1 & $\cdot / \Lambda \Delta$ & استفاده از اين فناورى سلامت به مديريت زمان كمك كرده است & rr & زمان انتظار \\
\hline 1 & 1 & 1 & 1 & استفاده از اين فناورى سلامت مى تواند زمان ارائه خدمت سلامت را كاهش دهد & re & \\
\hline 1 & 1 & 1 & 1 & با كاربرد اين فناورى زمان انتظار براى دريافت خدمت به مراتب كمتر مى شود & $r \Delta$ & \\
\hline 1 & $\cdot / \Lambda \Delta$ & 1 & 1 & اين فناورى سلامت اجازه استفاده از تجربه بالينى يرسنل سلامت را مى دهد & rq & اختيار \\
\hline 1 & 1 & 1 & 1 & اين فناورى سلامت اجازه تصميمات و انعطاف بذيرى در ارائه خدمت سلامت را به كاركنان سلامت مى دهد & rV & \\
\hline$\cdot / \Lambda \Delta$ & 1 & 1 & $\cdot / \wedge \Delta$ & مى توان درصورت لزوم از دستورات و راهنماى اين فناورى سلامت يِيروى نكرد & rA & \\
\hline 1 & 1 & 1 & 1 & انتخاب و بكار كيرى اين فناورى سلامت اختيارى مى باشد & rq & \\
\hline$\cdot / \wedge \Delta$ & 1 & 1 & 1 & براى به روز بودن بايد از اين فناورى سلامت استفاده كرد & r & \\
\hline 1 & 1 & 1 & $\cdot / \wedge \Delta$ & خدمات اين فناورى سلامت قابل اعتماد است & r & اعتمــاد و حفـظ إ \\
\hline 1 & 1 & 1 & 1 & اين فناورى سلامت دقت بالايى دارد & rt & 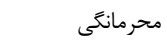 \\
\hline 1 & 1 & 1 & $\cdot / \wedge \Delta$ & تشخيص بيماريها توسط اين فناورى سلامت بهتر از تشخيص توسط انسان است & rr & \\
\hline
\end{tabular}


نشريه يزووهشده علوم بهداشتى جهاددانشحاهى

\begin{tabular}{|c|c|c|c|c|c|c|}
\hline$\cdot / \Lambda \Delta$ & 1 & 1 & 1 & اين فناورى سلامت خطاى يزشكى را كمتر مى كند & ry & \\
\hline 1 & 1 & 1 & 1 & اطلاعات و داده هاى ثبت شده در اين فناورى سلامت كاملا محرمانه مى باشد & ra & \\
\hline 1 & 1 & 1 & $\cdot / \Lambda \Delta$ & امنيت نكمهدارى و دسترسى به داده هاى اين فناورى سلامت بالا است & بs & \\
\hline 1 & 1 & 1 & $\cdot / \Lambda \Delta$ & استفاده اين فناورى سلامت باعث حفظ ارتباطات غيركلامى مانند ارتباط حشمى(جهره به جهره) مى شود & rV & 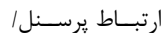 \\
\hline 1 & 1 & 1 & 1 & استفاده از اين فناورى سلامت باعث حفظ ارتباط كلامى بين يرسنل سلامت و بيمار مى شود & rᄉ & بيمار(كيرنــــــــه \\
\hline 1 & 1 & 1 & $\cdot / \Lambda \Delta$ & اين فناورى سلامت به درك متقابل يرسنل سلامت و كيرنده خدمت(بيمار) كمك ميكند & rq & 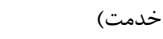 \\
\hline$\cdot / \wedge \Delta$ & $\cdot / \wedge \Delta$ & $\cdot / \wedge \Delta$ & $\cdot / V Q$ & اين فناورى سلامت به حفظ ارتباط همدلانه و تسكين دادن به بيمار توسط ٍرسنل سلامت كمك مى كند & r. & \\
\hline 1 & $\cdot / \Lambda \Delta$ & $\cdot / \wedge \Delta$ & $\cdot / \Lambda \Delta$ & اين فناورى سلامت به ابراز همدردى يرسنل سلامت با كيرنده خدمت(بيمار) كمك مى كند & il & \\
\hline 1 & 1 & 1 & $\cdot / V Q$ & اين فناورى سلامت به حفظ همكارى متقابل بين يرسنل سلامت و بيمار كمك مى كند & et & \\
\hline 1 & 1 & 1 & 1 & تمايل دارم اين فناورى سلامت را در آينده نيز استفاده كنم & pr & قصد استفاده \\
\hline 1 & 1 & 1 & 1 & تمايل دارم از اين فناورى سلامت به طور مداوم استفاده كنهم & fr & \\
\hline 1 & 1 & 1 & 1 & استفاده از اين فناورى سلامت را به ديكران توصيه مى كنم & is & \\
\hline
\end{tabular}

جدول r: مقادير بدست آمده تحليل عاملى براى تعيين كننده ها و كويه هاى مربوطه

\begin{tabular}{|c|c|c|c|c|c|}
\hline ميانگين(M) & وزن & T Statistics & بارعاملى & كويه & تعيين كننده \\
\hline$\Lambda \Delta \Gamma / \cdot$ & $\langle\wedge 1 /$. & $F V T / r \Delta$ & $\Lambda \Delta Y / \cdot$ & PE1 & $\overline{\mathbf{P E}}$ \\
\hline$\Lambda F \Lambda /$. & $r V F /$. & $r \Delta F / f \psi$ & $\Lambda F \wedge /$. & PE2 & \\
\hline$\Delta \vee \backslash /$. & rqV/. & IIr/ar & $\wedge \notin q /$. & PE3 & \\
\hline$\wedge \vee \& /$. & $r \cdot \Lambda / \cdot$ & $\Delta \vee q / q)$ & $\Lambda \vee \Delta /$. & PE4 & \\
\hline$\Lambda \Lambda) /$. & $\mathrm{r \Lambda N} / \cdot$ & $\Delta \Lambda F / 94$ & $\Lambda \Lambda Y /$. & EE1 & $\mathbf{E E}$ \\
\hline$\Lambda \Delta \xi /$. & $r \cdot q /$. & $199 / 4 \Delta$ & $\Lambda \Delta \varepsilon /$. & EE2 & \\
\hline$\Lambda M T /$. & $r q 4 /$. & $r q \mu / \Delta f$ & $\Lambda \Lambda T /$. & EE3 & \\
\hline ATr/. & TrI/. & $r T F / T V$ & NKr/. & EE4 & \\
\hline 1) & $\mid \Lambda F /$. & $1 q F / r F$ & 1191. & $\mathrm{FC} 1$ & FC \\
\hline$V \Delta S /$. & $\mid V F /$. & $V \Delta G / I T$ & VG9/. & FC2 & \\
\hline 9.91. & $199 /$. & $\Delta T F / I I$ & 41.1. & FC3 & \\
\hline VKT/. & $\mid V r / \cdot$ & $994 / 1 T$ & $V \Delta r /$. & $\mathrm{FC} 4$ & \\
\hline$\Lambda \Delta \mathrm{V} / \cdot$ & THY/. & $191 / 4$. & $\wedge \Delta q / \cdot$ & FC5 & \\
\hline$\Delta \cdot \Lambda / \cdot$ & זाr/. & $\vee q 4 / q$ & $\Delta \cdot \psi /$. & FC6 & \\
\hline$G \cdot V /$. & $r \cdot r / \cdot$ & . ID/IT & GाTा. & FC7 & \\
\hline$\Lambda \cdot \Lambda /$. & rAV/. & $F q r / r F$ & $\Lambda \cdot \Lambda / \cdot$ & PV 1 & PV \\
\hline$q \cdot r / \cdot$ & TrQ/. & TVV/A. & $q \cdot r / \cdot$ & PV 2 & \\
\hline$\Delta K F /$. & 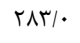 & $V D T / F Y$ & . & PV 3 & \\
\hline$\Lambda \mathrm{IV} /$. & ГАК $/$. & ג & $11 \% /$. & PV 4 & \\
\hline QTY/. & $r<q /$. & AGT/AT & 9Tr/. & HB 1 & HB \\
\hline$\Lambda \Lambda \mathrm{V} /$. & THEF/. & AVT/Gr & $\Lambda \wedge \mathrm{V} /$. & HB 2 & \\
\hline 91.1. & $\uparrow \cdot q /$. & $V V I / A$. & $911 /$. & HB 3 & \\
\hline$\lambda \mid F /$. & FYN/. & $F r \cdot|\Delta|$ & $\Lambda \mid \& /$. & WT 1 & WT \\
\hline$\Lambda M N /$. & $r q q /$. & VET/VT & $\wedge \wedge q /$. & WT 2 & \\
\hline • & TrYl/. & $\varepsilon \Delta s / r q$ & $\Lambda \mu F /$. & WT 3 & \\
\hline$\wedge १ १ /$. & $|F| r /$. & GQN/DF & $\wedge q . /$. & AU1 & $\mathbf{A} \mathbf{U}$ \\
\hline ATr/. & $r \cdot r / \cdot$ & $\Delta \& N / T$. & $\Lambda T F /$. & AU2 & \\
\hline$\Lambda .81$. & $r \cdot 8 /$. & $\checkmark \wedge \Lambda / I \Lambda$ & $\Lambda \mid \Delta /$. & AU3 & \\
\hline$\Delta 11 /$. & $.9 \% / \cdot$ & $q \wedge \Delta / \uparrow$ & $\Delta T F /$. & AU4 & \\
\hline VRq/. & TrE/. & $1 \pi \cdot / l f$ & $V r V /$. & AU5 & \\
\hline - /VGA & . ITTS & . rF/TV & VEN/. & TR1 & TR \\
\hline - IVFA & $\cdot \pi \mid r$ & Tr/GIT & $\cdot / v \& q$ & TR2 & \\
\hline - |NSV & . ITF. & G9/9r & $\cdot \mid \Lambda \& V$ & TR3 & \\
\hline . MVT & . Krq & $r 9 / 119$ & $\cdot \mid V V I$ & TR4 & \\
\hline$\cdot 11 \cdot 9$ & $\cdot / \pi 11$ & $r V / l F F$ & $\cdot 11 \cdot 9$ & TR5 & \\
\hline 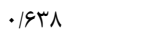 & $\cdot / / \vee \Delta$ & $|V| G \mid G$ & . $\mid q T V$ & TR6 & \\
\hline.$/ 915$ & $\cdot|r \wedge|$ & GN/G9. & $.191 \mathrm{r}$ & RE1 & \\
\hline$\cdot \mid \Lambda \Lambda$. & . /TAV & rG/rTV & - /ANK & RE2 & \\
\hline
\end{tabular}




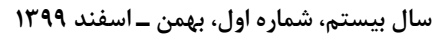

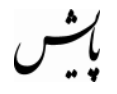

\begin{tabular}{|c|c|c|c|c|c|}
\hline \multicolumn{4}{|c|}{ غلامرضا ملك زاده و همكاران } & & \multirow[t]{2}{*}{ واكاوى عوامل موثر بر يذيرش ... } \\
\hline. $\mid 991$ & $\cdot / \cdot r$. & $9 / 419$ & $.19 V \Delta$ & RE3 & \\
\hline$\cdot / V V V$ & $\cdot / 411$ & 19/FTr & $\cdot / V \wedge \mid$ & RE4 & $\mathbf{R E}$ \\
\hline$\cdot / V \wedge V$ & $\cdot / 1 r$. & IT/VFF & $\cdot \mid 1 \cdot 1$ & RE5 & \\
\hline ./V१९ &.$/ 1 r q$ & $1 \% / 991$ & . & RE6 & \\
\hline.$/ 94 \wedge$ & . Ifre & $111 / 911$ & . $/ 94 \wedge$ & BI1 & BI \\
\hline . 1 Arq & $\cdot / r \Delta \Delta$ & $r \cdot / r F \Delta$ & . IArq & $\mathrm{BI} 2$ & \\
\hline$\cdot|\lambda f|$ & שU & rF/VIT & $\cdot|\lambda f|$ & $\mathrm{BI} 3$ & \\
\hline
\end{tabular}

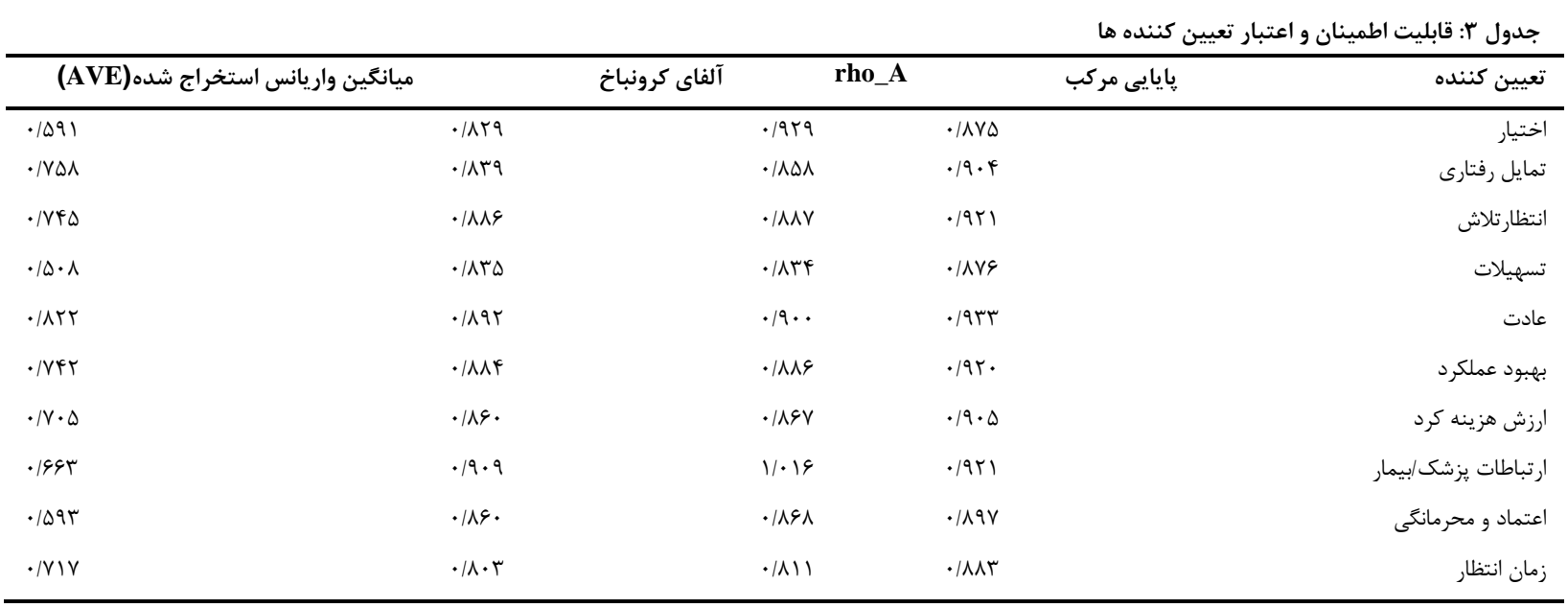

جدول ه: ضريب تعيين بدست آمده

\begin{tabular}{|c|c|c|c|}
\hline & BI & $\begin{array}{r}\text { R Square } \\
\cdot / \wedge \uparrow \Delta\end{array}$ & $\begin{array}{r}\text { R Square Adjusted } \\
\cdot / \Lambda \uparrow \uparrow\end{array}$ \\
\hline \multicolumn{4}{|c|}{ جدول \&: مجموع مجذورات مشاهدات، مجموع مجذور خطاهاى پِيش بينى و معيار استون - كيزر براى هر تعيين كننده } \\
\hline $\mathrm{Q}^{2}(=1-\mathrm{SSE} / \mathrm{SSO})$ & SSE & SSO & تعين كننده \\
\hline •/ १९९ & 1,ז $\Delta \wedge / q \wedge \varepsilon$ & $r / \cdot \wedge \Delta$ & اختيار \\
\hline$\cdot$ / FVG & $9 \Delta \Delta / I V T$ & $1 / T \Delta 1$ & تمايل رفتارى \\
\hline . IOHG & $V V F / 4 q V$ & $1 / 991$ & انتظار تلاش \\
\hline - & $1,91 \wedge / r \wedge$ & $r / 919$ & تسهيلات \\
\hline$\cdot \mid \Delta \& \Lambda$ & $\Delta F \cdot / 9 q r$ & $1 / T \Delta 1$ & عادت \\
\hline . IDTt & $V \lambda \cdot / 410$ & $1 / 991$ & بهبود عملكرد \\
\hline$\cdot / 4 \wedge F$ & $\wedge \notin \mid / 4 \& 4$ & $1 / 991$ & ارزش هزينه كرد \\
\hline$\cdot|\Delta| \Lambda$ & $1, r \cdot V / 191$ & $r / \Delta \cdot r$ & ارتباطات يزشك/بيمار \\
\hline . IfTE & $1, F r \Delta / \Lambda \cdot 1$ & $r / Q \cdot r$ & اعتماد و محرمانكى \\
\hline$\cdot / 4 \cdot 4$ & VFT/FVD & $1 / T \Delta 1$ & زمان انتظار \\
\hline
\end{tabular}

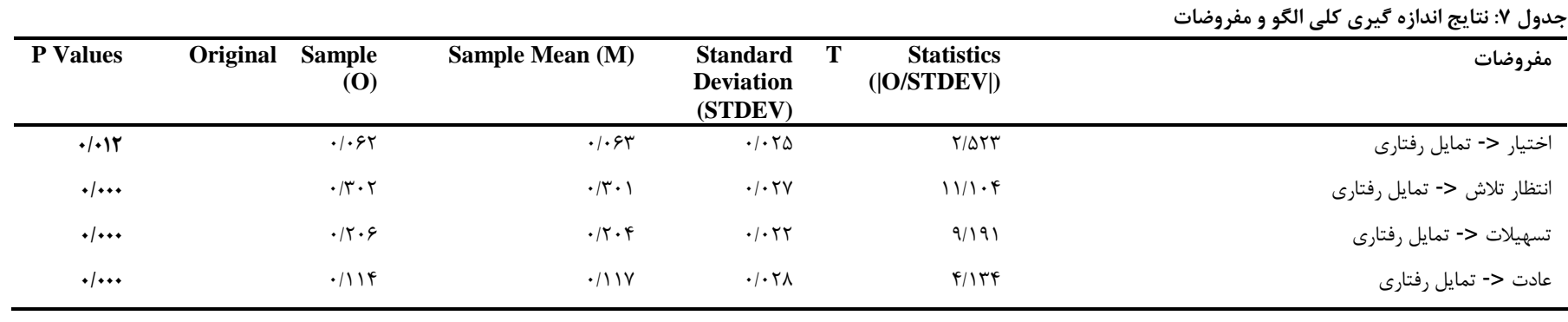


سال بيستم، شماره اول، بهمن _اسفند 99 19

نشريه يزوهشكده علوم بهداشتى جهاددانشكاهى

\begin{tabular}{|c|c|c|c|c|c|}
\hline $.1 \ldots$ & $\cdot / 1 \wedge \uparrow$ & - /1イr & $\cdot / \cdot T V$ & $9 / V \cdot 9$ & انتظار عملكرد >- تمايل رفتارى \\
\hline $.1 \cdots$ &.$/ 149$ & $\cdot / 1 \uparrow \Lambda$ & $\cdot 1 \cdot \mathrm{rq}^{2}$ & $\Delta / / V \Delta$ & ارزش قيمت >- تمايل رفتارى \\
\hline$\cdot 1 \cdot 11$ & -.1 .94 & -.1 .4 & $.1 \cdot r_{\Delta}$ & $r / \Delta \Delta \mid$ & ارتباطات >- تمايل رفتارى \\
\hline $.1 \cdots$ &.$/ 1 V r$ & $\cdot / l V F$ & $\cdot 1 \cdot r \Lambda$ & $9 / \pi I^{4}$ & اعتماد و محرمانتى >- تمايل رفتارى \\
\hline $.1 \ldots$ & $\cdot / 1 \Delta \Delta$ & . /NAT & $.1 . r 4$ & $91 \cdot 00$ & زمان انتظار >- تمايل رفتارى \\
\hline
\end{tabular}

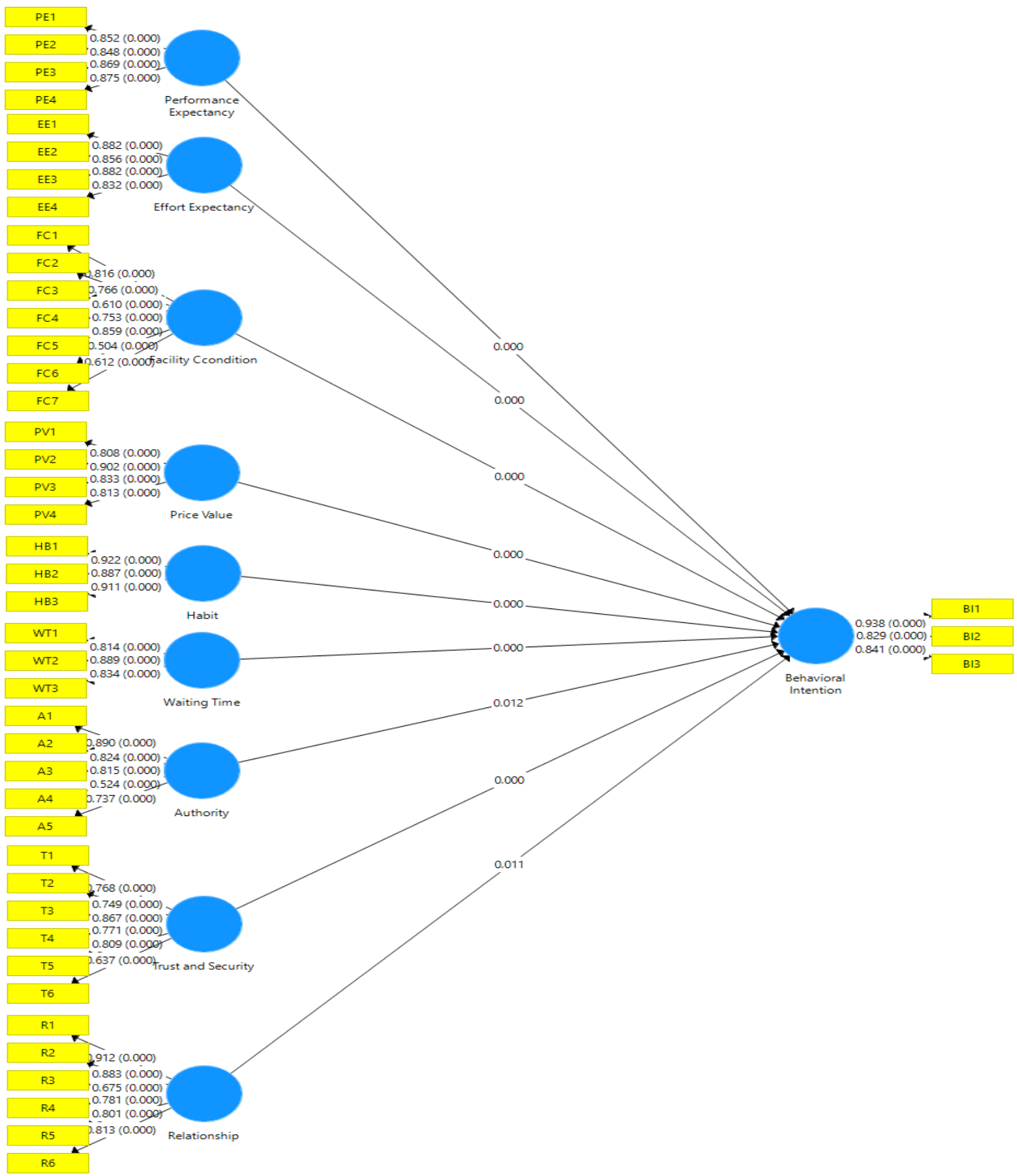

شكل ا: نتايج اجراى الكَوى نهايى تحقيق 
بيشترى دارد كه فنــاورى هـاى خاصسى را بيذيرنـد، كـهـ بـهـ وجــود

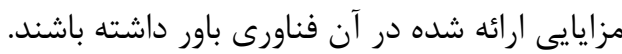

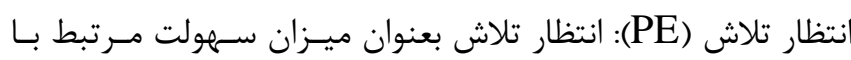
بكارگيرى اين سيسـتم تعريـف مسى شـود كـهـ بركرفتـهـ از مفـاهيم

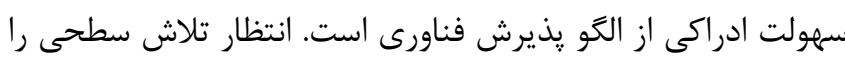

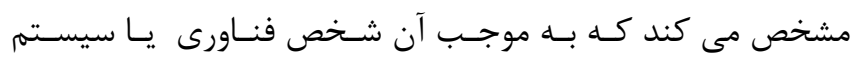

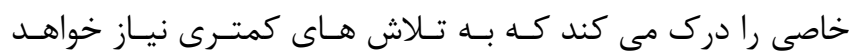

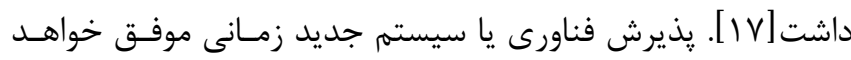

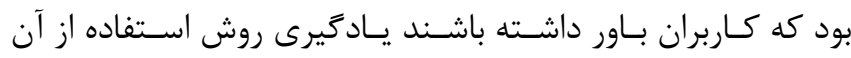

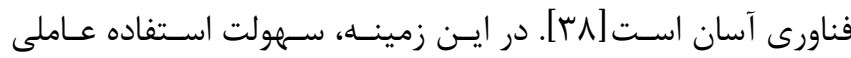

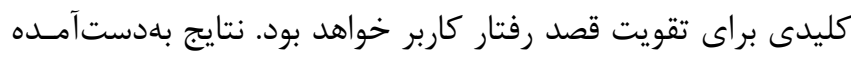

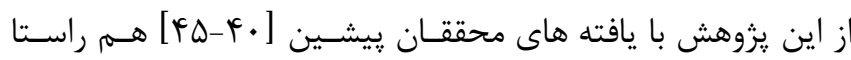

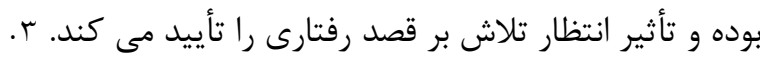

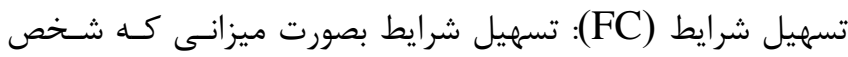
باور مى كند كه زير ساخت فنى و سازمانى براى يشتيبانى اسـتفاده

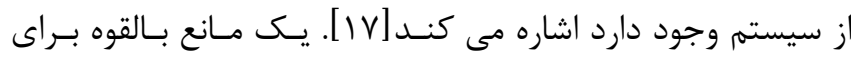

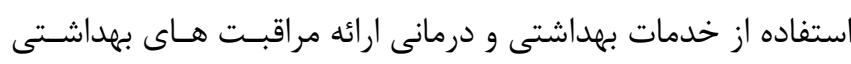
عدم وجود منابع يا خدمات يشتيبانى است كــهـ بــهـ كـاربران امكــان

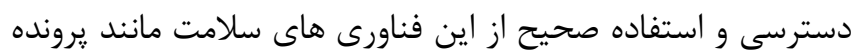

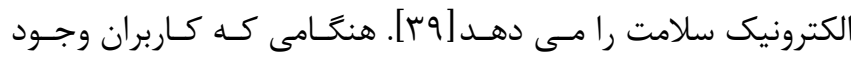
امكانات فنى و منابع براى حمايت از سيسـتم را بـاور دارنـد، انتظــار

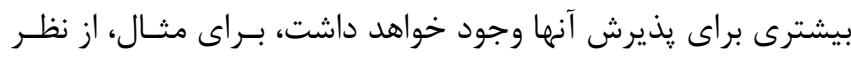

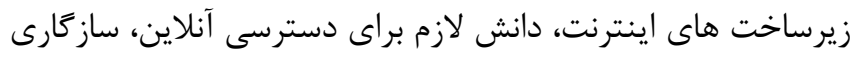

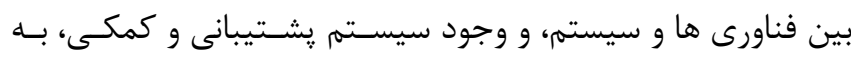

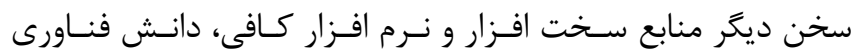

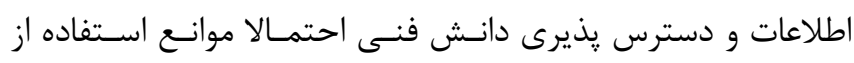

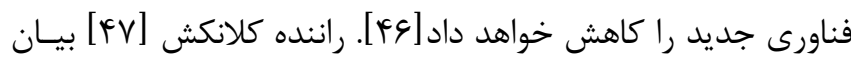
مى كند كه زير ساخت اطلاعات سلامت ملى از مهـهم تـرين عوامـل رهل موثر جهت عرضه مراقبت هاى بهداشتى مبتنى بر فناورى اسـت. در

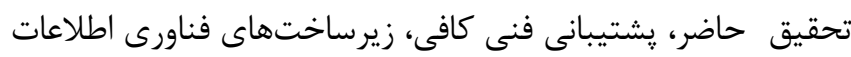

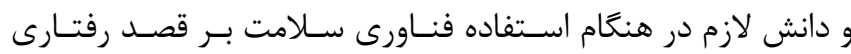

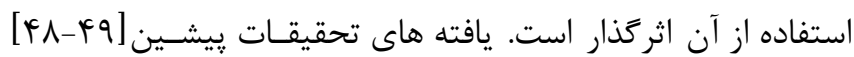

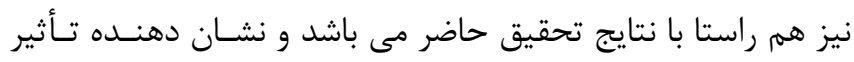
تسهيل كننده ها بر قصد رفتارى است. ارزش هزينه كرد(PV): ساختار هزينه و قيمت ممكن اسـت تـأثير

\section{بحث و نتيجه گيرى}

اگر عوامل موثر بر يذيرش شناسايى و درك شود طرح ريزى بهتـر و

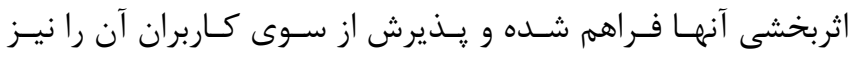

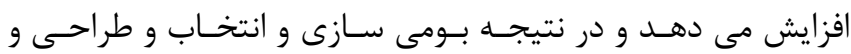
استقرار فناورى هاى سلامت به درستى صورت گرفته و از هدر رفت

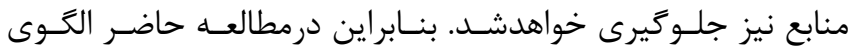

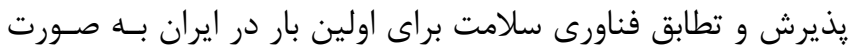

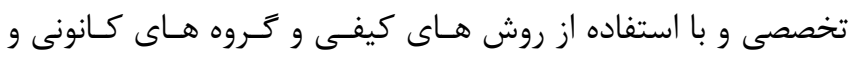
علاوه براين تحليل عاملى تائيدى و با تكيه بر الخـو سـازى معـادلات

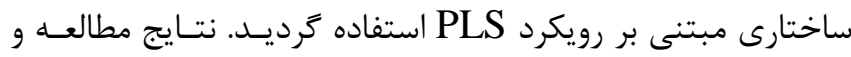

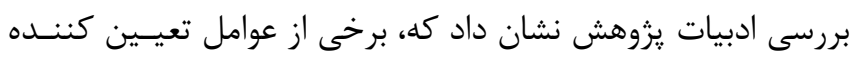

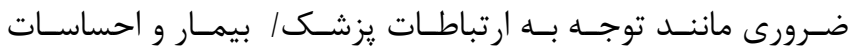

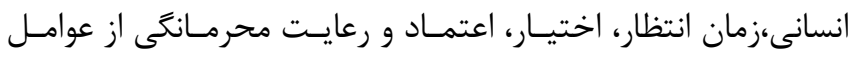

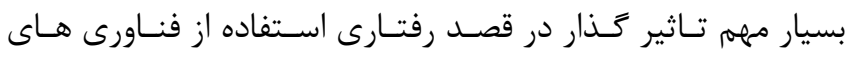
سلامت مى باشد كه به عنوان عوامل جديد به الخَـوى UTAU2

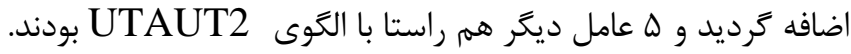
در اين راستا عوامل استخراجى الگو به شرح ذيل مى بـ باشد:

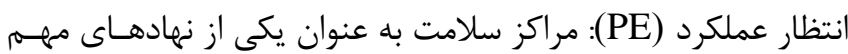
خدماتى جامعه در حوزه ييگيرى و نظارت نقش قابل توجهـى دارنــد

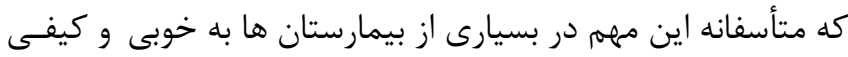

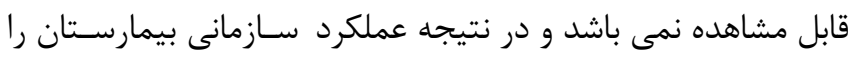

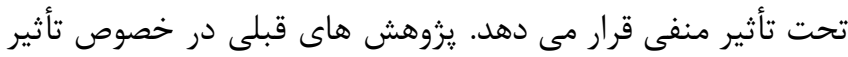

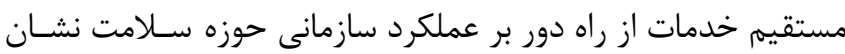

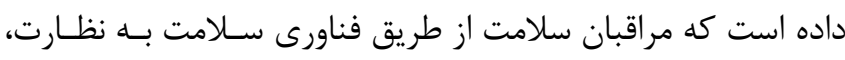

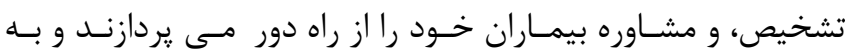

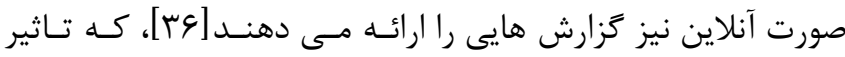

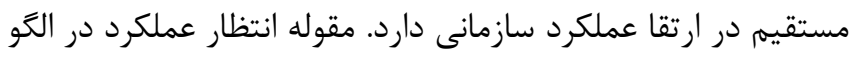
يذيرش فناورى قوى ترين پيش بينى كننده براى تمايل به اسـتفاده

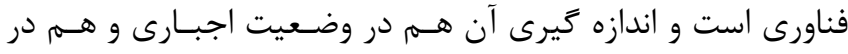
وضعيت اختيارى استفاده از فناورى معنادار بـاقى مسى مانــد. نتــايج

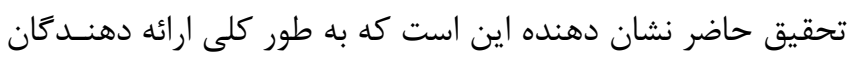

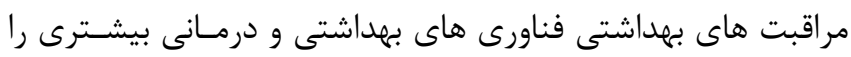

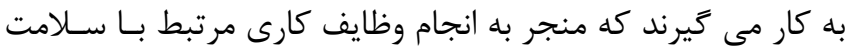

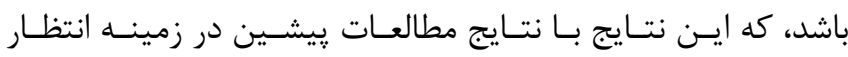

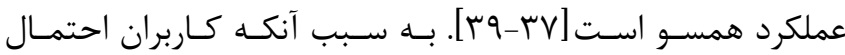


اهداف عادت و رفتارهاى ناشى از عادت نشان داده است كـه عـادت

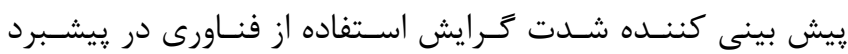

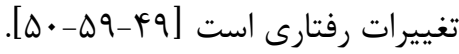

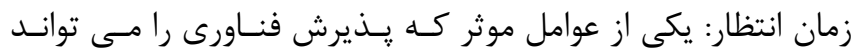

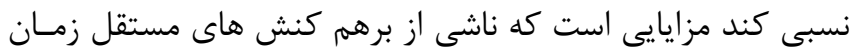

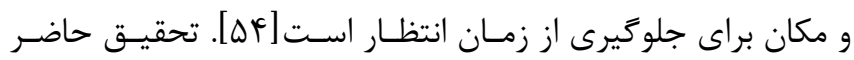

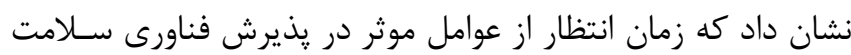

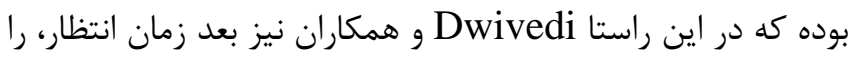

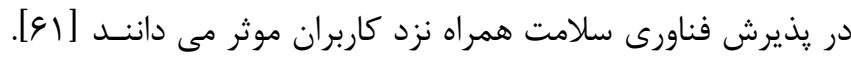

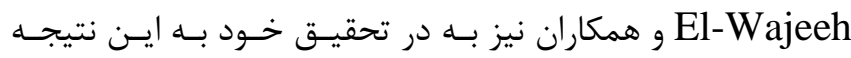
رسيدند كه ذخيره زمان ناشى از استفاده از فنـاورى سـلامت سـبب ندان

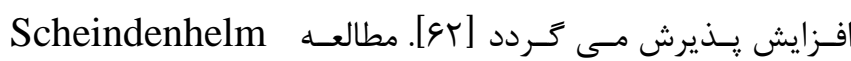
Kossman آن در يذيرش فناورى اشاره شده است [بَّ].

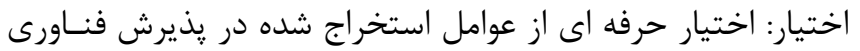
سلامت در تحقيق حاضر بود. ساير تحقيقات همراستا نيز نشان داده اند كه هنخامى كه فناورى بر نقش هاى شغلى، وضعيت حرفـه ائ و

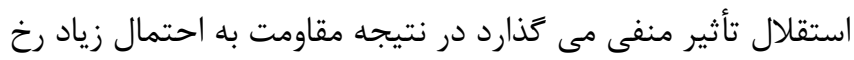

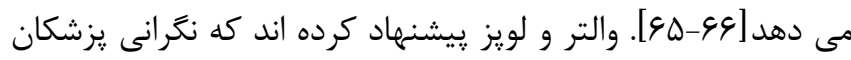

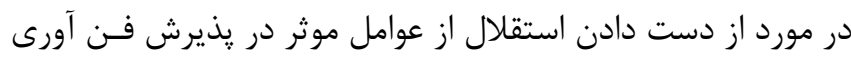

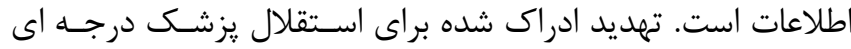

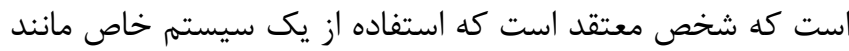

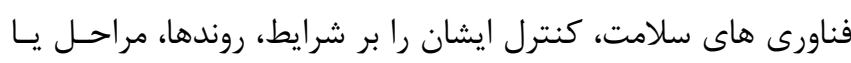
محتواى كار كاهش مى دهد [عهاى]. اعتماد و محرمانه بودن اطلاعات بيمار: يافته ها نشان داد كه اعتمـاد

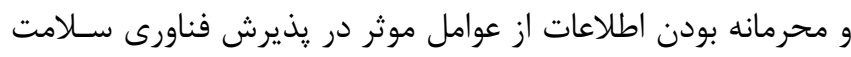

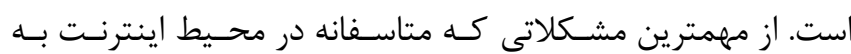

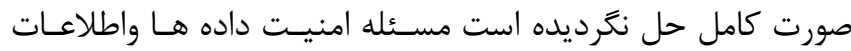

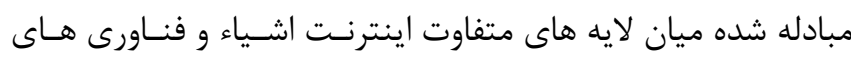

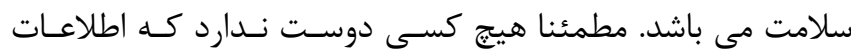
محرمانه يزشكى او توسط هكرها به سرقت رود. دسترسى غير مجـاز

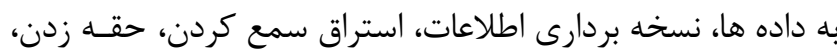

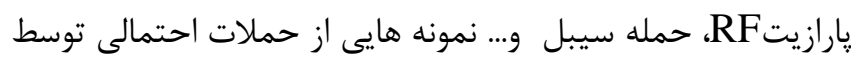

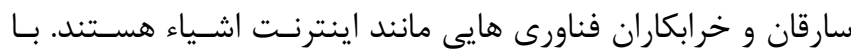
توجه به اينكه امنيت اطلاعات و كنترل داده هاى بهداشتى هر بيمار ائنار

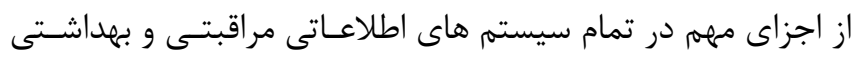

قابل توجهى در استفاده از فناورى داشته باشد. ارزش هزينه، ميـزان ارزش ادراك شده توسط كاربر فناورى است كه مى تواند در انتخاب

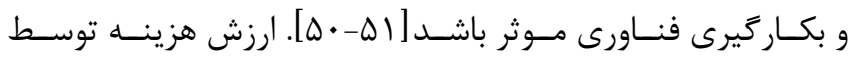
محققين در زمينه فناورى اطلاعات و بازارهاى مرتبط بــا تجهيـزات

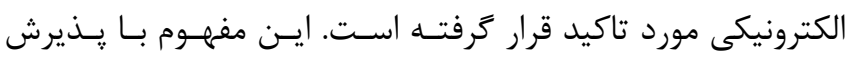

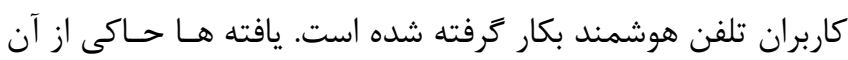

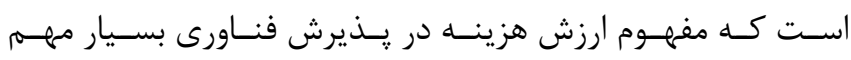

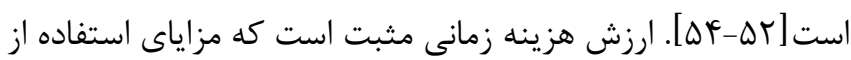

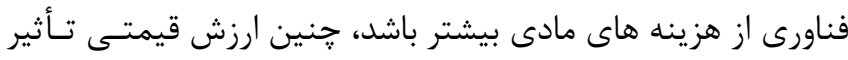

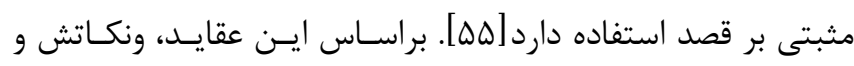

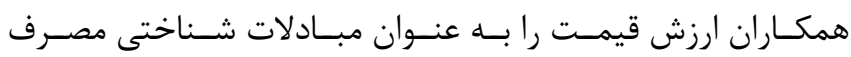

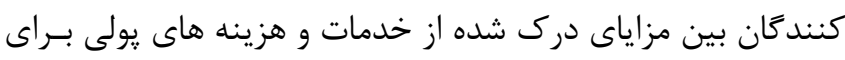

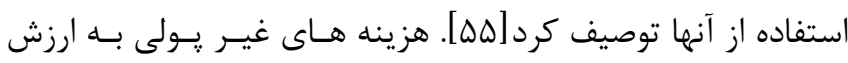
مشخص شده در ازاى هزينه هايى از قبيل زمان و تلاش صرف شده است. در تحقيق حاضر، ارزش قيمت هم ارزشهاى يولى و هـهم غيــر

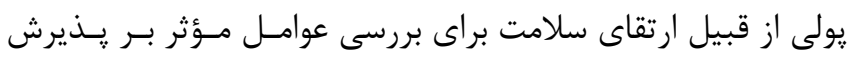
فناورى يرونده الكترونيك سلامت است. عادت: عادت به فناورى آخرين عاملى بود كه توسـ لفـ Venkatesh

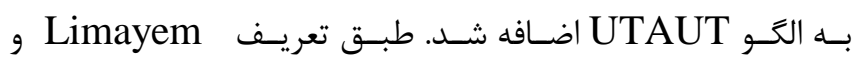

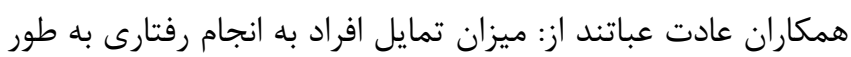

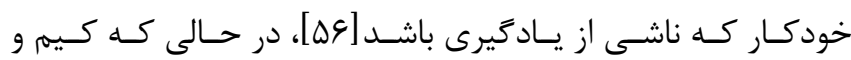

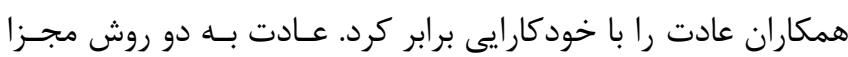

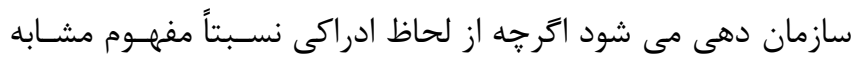

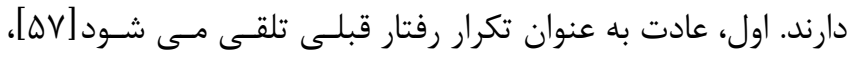

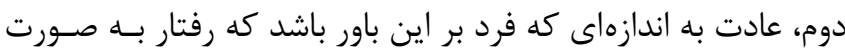

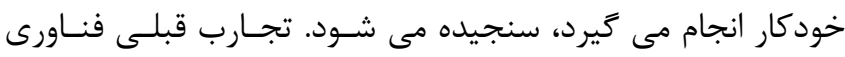

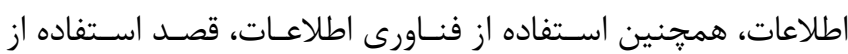

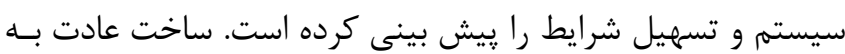

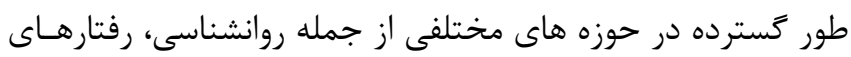

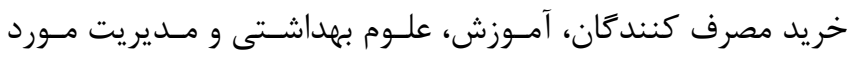

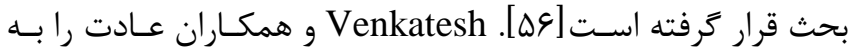

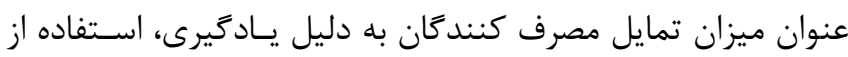

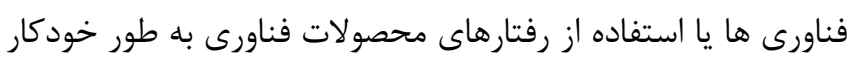

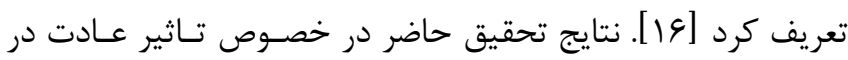

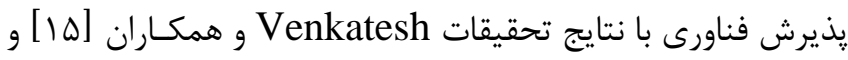

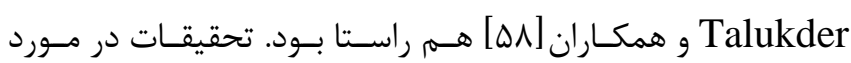


از تأمين نمايند. بنابر اين لازم است در طراحى فناورى هاى سلامت

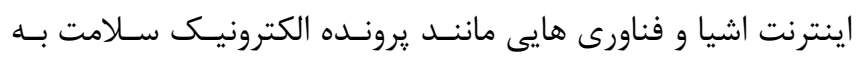

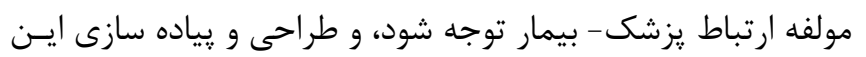

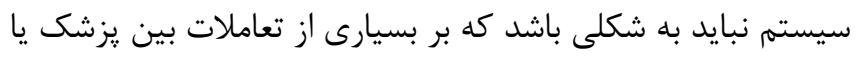

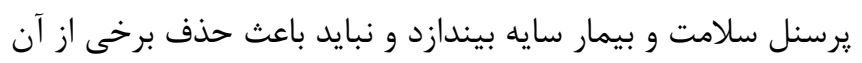

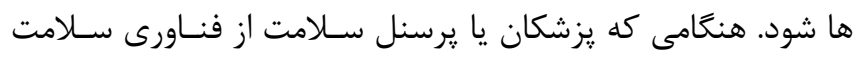

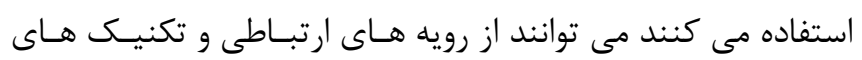

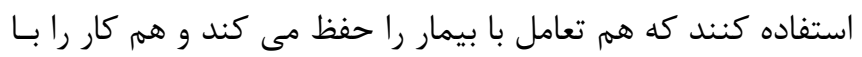
فناورى امكان קذير كند.

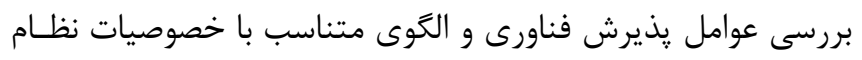

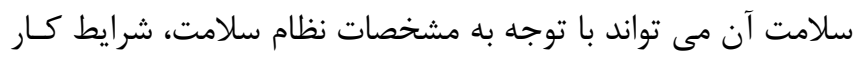

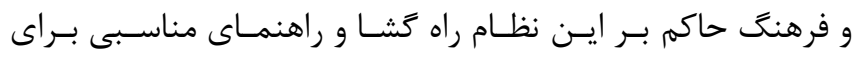

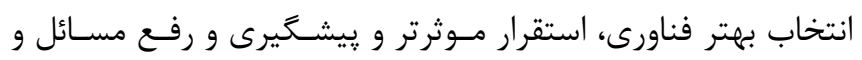

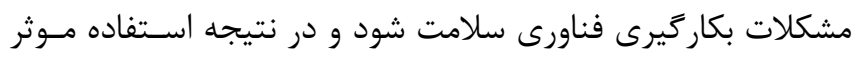

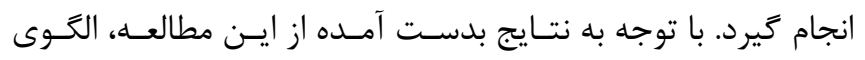

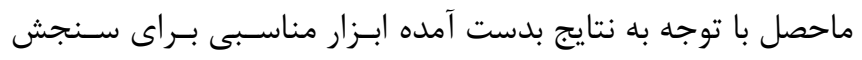

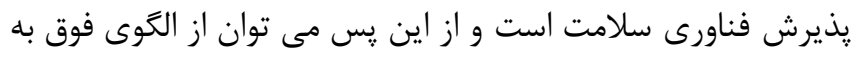

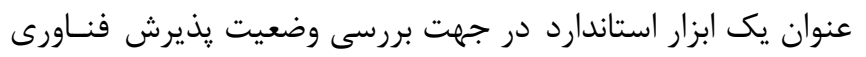
سلامت و شناسايى عوامل موثر آن استفاده نمود.

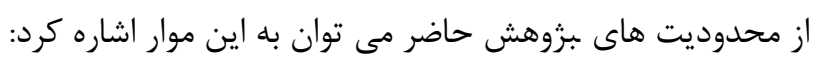

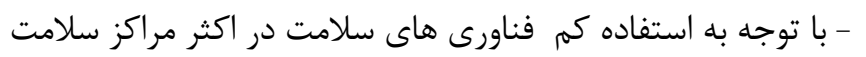

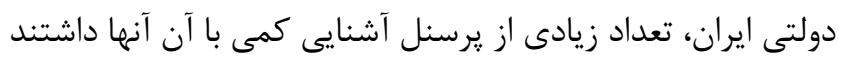

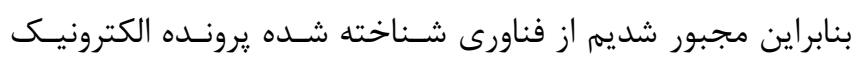

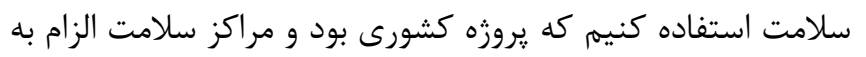

$$
\text { استفاده از آن هستند. }
$$

- كمبود تحقيقات مشابه در زمينه موضـوع تحقيـق موجـب صـرف آندان زمان بيشتر براى تهيه اطلاعات دقيق شد.

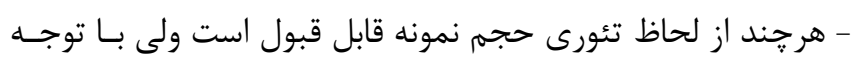

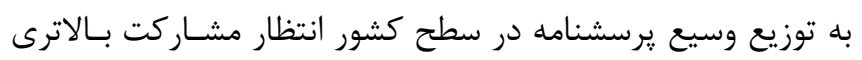

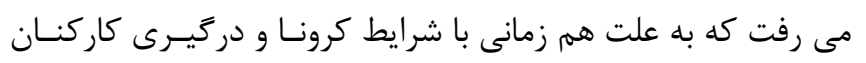
سلامت با كرونا حجم نمونه تحت تاثير قرار كرفت.

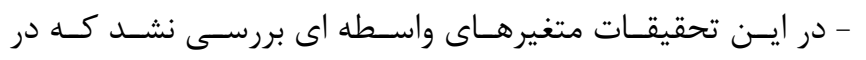

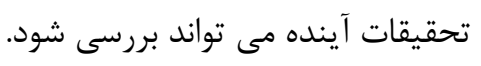

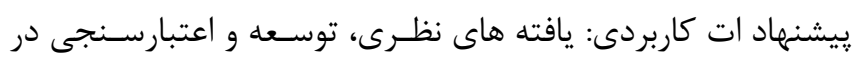

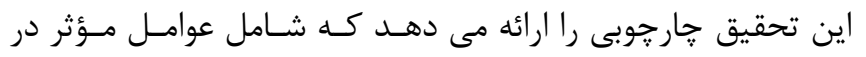

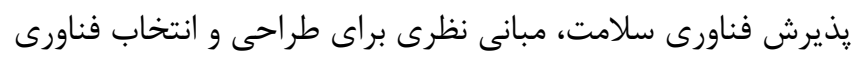

مى باشد، انتقال الكترونيكى نامناسـب و عـدم اسـتفاده مطلـوب از

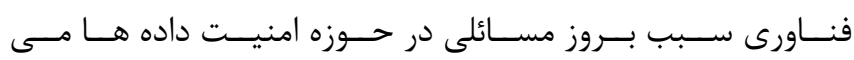

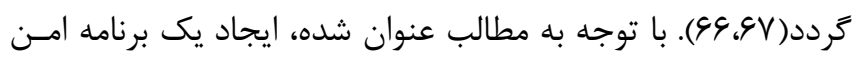

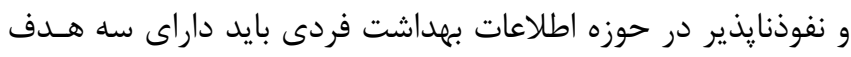

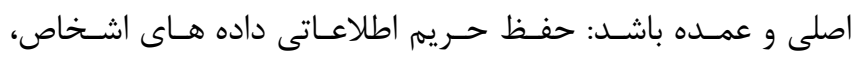

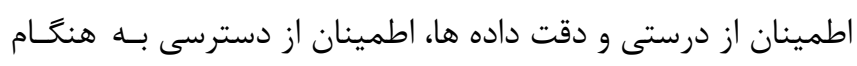

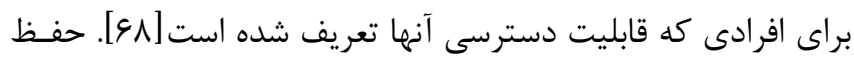

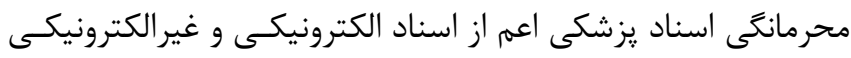

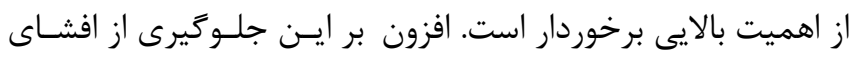

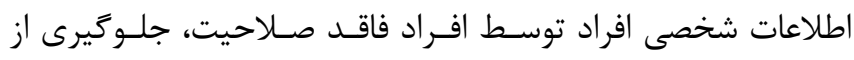

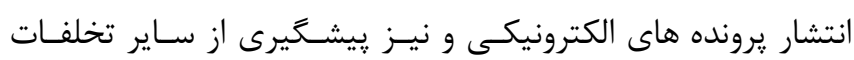

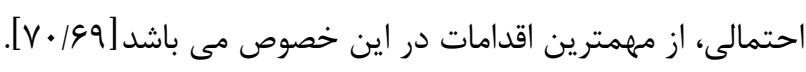

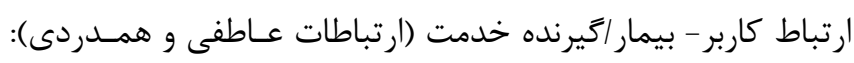

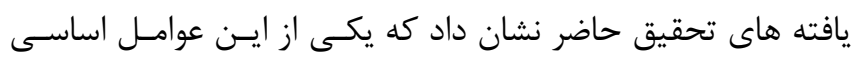

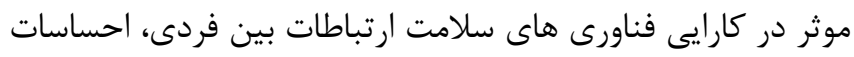

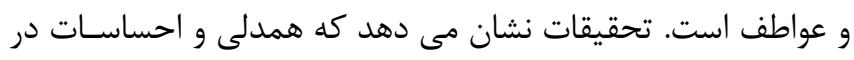

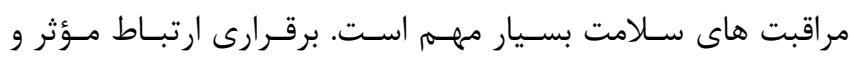

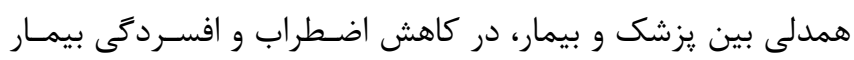

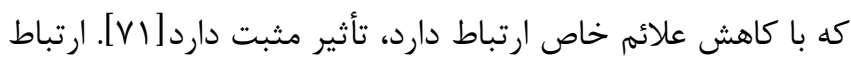

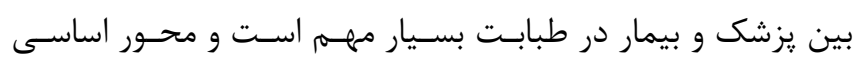

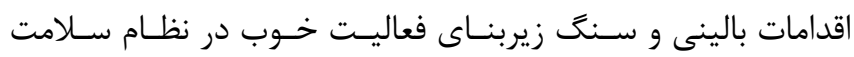

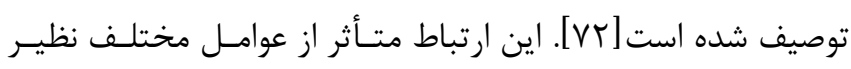

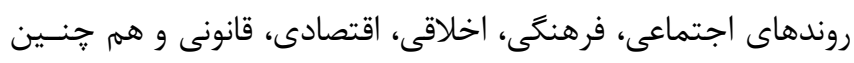

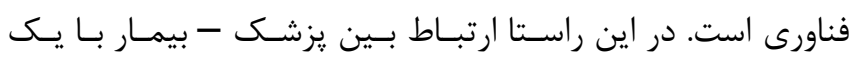

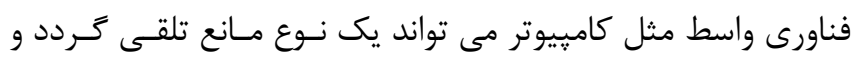

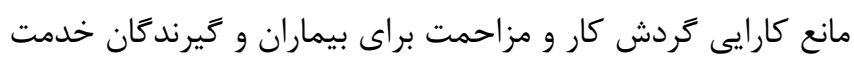

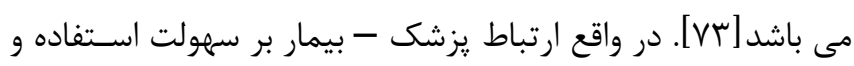

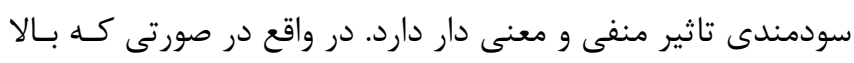

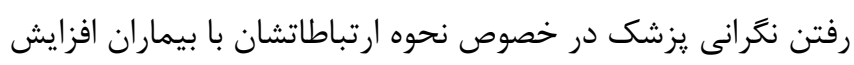

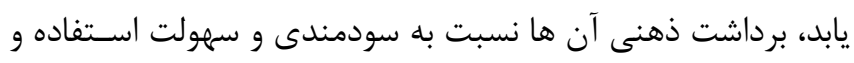

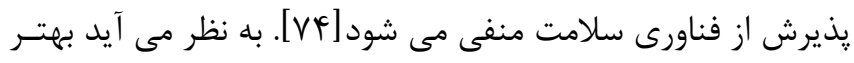

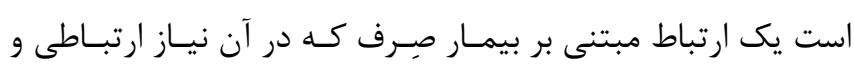

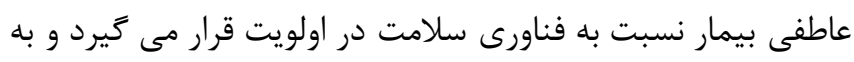

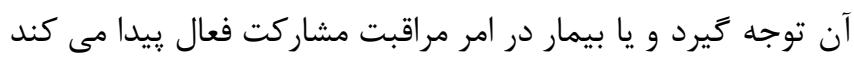

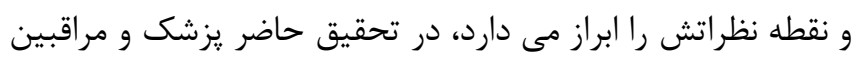

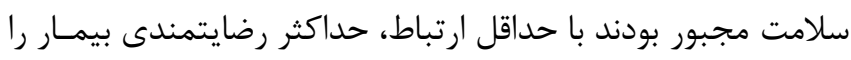




$$
\begin{aligned}
& \text { غلامرضا ملك زاده: راهنمايى، نظارت و ويرايش } \\
& \text { ماريوش تراجونويسكى: استاد مشاوره } \\
& \text { تشكر و قدردانى }
\end{aligned}
$$

اين مقاله حاصل رساله دكترى مديريت (كرايش رفتارسازمانى) دوره

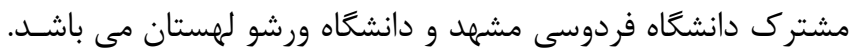
يزوهشگر بر خود واجب مى داند تا از تمـامى كســـى كــه در انجـام

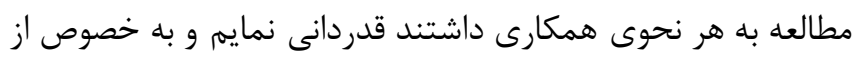

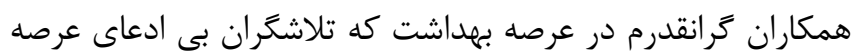
سلامت بوده و با تمام وجود خط مقدم مبارزه با كرونا را حفظ كرده

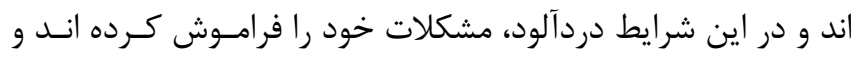
فكر سلامتى مردم شب و روزشان را بر كرده است تشكر نمايم.

\section{منابع}

1. Akematsu Y, Tsuji M. An empirical approach to estimating the effect of e-health on medical expenditure. Journal of Telemedicine and Tele care 2010; 16:169-71

2. Wickramasinghe NS, Fadlalla AM, Geisler E, Schaffer JL. A framework for assessing e-health preparedness. International Journal of Electronic Healthcare 2005 1; 1:316-34

3. Maheu M, Whitten P, Allen A. E-Health, Telehealth, and Telemedicine: a guide to startup and success. $1^{\text {st }}$ Edition, John Wiley \& Sons: Uk, 2002

4. Tan Y. Feeling Blue? Go Online: An Empirical Study of Social Support Among Patients. Information Systems Research 2014; 25: 690-709

5. Hannan TJ, Celia C. Are doctors the structural weakness in the health building? Internal Medicine Journal 2013; 43:1155-64

6. Anderson JG, Balas EA. Computerization of primary care in the United States. International Journal of Healthcare Information Systems and Informatics (IJHISI) 2006 1; 1:1-23

7. Terry AL, Thorpe CF, Giles G, Brown JB, Harris SB, Reid GJ, Thind A, Stewart M. Implementing electronic health records: Key factors in primary care. Canadian Family Physician 2008 1; 54:730-6

8. Wager KA, Lee FW, Glaser JP. Health care information systems: a practical approach for health care management. $1^{\text {st }}$ Edition, John Wiley \& Sons: UK, 2017

$$
\begin{aligned}
& \text { در مراقبت هاى بهداشتى آينده قبل از ورود آنهـا بـهـ بــازار يـا رفـع } \\
& \text { مشكلات يذيرش آنها بعد از ورود فناورى باشد. }
\end{aligned}
$$

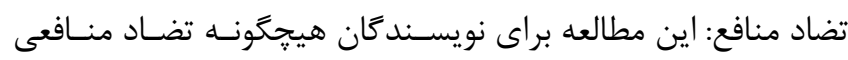

$$
\begin{aligned}
& \text { نداشته است. } \\
& \text { ملاحظات اخلاقى: اين مطالعه در كمته اخـلاق در يـزروهش دانشـعاه }
\end{aligned}
$$

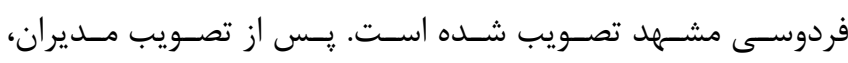

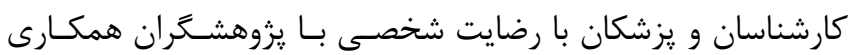

$$
\begin{aligned}
& \text { كردند. نام مشاركت كنندگان ذكر نشده و محرمانه است. } \\
& \text { سهم نويسند } \\
& \text { عارف شايعان مهر: جمع آورى داده ، نعارش مقاله، تجزيه و تحليل } \\
& \text { و جمع بندى }
\end{aligned}
$$

9. Backer TE. Reviewing the behavioral science knowledge base on technology transfer. $1^{\text {st }}$ Edition, United States Government Printing: USA, 1995

10. Kim HW, Kankanhalli A. Investigating user resistance to information systems implementation: A status quo bias perspective. MIS quarterly 2009 1:56782

11. Poon EG, Blumenthal D, Jaggi T, Honour MM, Bates DW, Kaushal R. Overcoming barriers to adopting and implementing computerized physician order entry systems in US hospitals. Health Affairs 2004; 23:184-90

12. Nair SV. Benefits and security of electronic health record (EHR) use by pediatric staff: a technology acceptance model (TAM)-based quantitative study [Thesis]. USA: Capella University; 2011

13. Wilkins MA. Factors influencing acceptance of electronic health records in hospitals. Online Research Journal Perspective in Health Information Management 2009; 6: 1

14. Alanazy S. Factors associated with implementation of electronic health records in Saudi Arabias [Theseis]. HKU: The University of Hong Kong 2006.

15. Morton ME. Use and acceptance of an electronic health record: factors affecting physician attitudes [Thesis]. USA: Drexel University 2008 16. Venkatesh V, Thong JY, Xu X. Consumer acceptance and use of information technology: extending the unified theory of acceptance and use of technology. MIS quarterly 2012; 1:157-78 
17. Venkatesh V, Morris MG, Davis GB, Davis FD. User acceptance of information technology: Toward a unified view. MIS quarterly 2003; 1:425-78 18. Herrero Á, San Martín H. Explaining the adoption of social networks sites for sharing usergenerated content: A revision of the UTAUT2. Computers in Human Behavior 2017; 71:209-17

19. Slade EL, Williams MD, Dwivedi Y. An extension of the UTAUT 2 in a healthcare context. In UK AIS 2013; 19: 55

20. Hsu CL, Lin JC. An empirical examination of consumer adoption of Internet of Things services: Network externalities and concern for information privacy perspectives. Computers in Human Behavior 2016; 62:516-27

21. Kim S, Kim S. User preference for an IoT healthcare application for lifestyle disease management. Telecommunications Policy 2018; 42:304-14

22. Götz O, Liehr-Gobbers $\mathrm{K}$, Krafft $M$. Evaluation of structural equation models using the partial least squares (PLS) approach. In Handbook of partial least squares. $1^{\text {st }}$ Edition, Springer: Berlin, Heidelberg, 2010

23. Mohsenin S, Esfidani MR. Structural Equation Modeling with the partial least squares (PLS) approach using the software Smart PLS. $1^{\text {st }}$ Edition, Institute Ketone Mehraban Publication: Tehran, 2015 [InPersian]

24. Fornell C, Larcker DF. Evaluating structural equation models with unobservable variables and measurement error. Journal of Marketing Research 1981; 18:39-50

25. Ghazi Tabatabaee M. Lisrel methods, and describes the structure and logic underlying the analysis methods, Covariance structure models or LISREL in social scince. Journal of Litrature Faculty of Tabriz University 1995:2:3 [InPersian]

26. Werts CE, Linn RL, Jöreskog KG. Intraclass reliability estimates: Testing structural assumptions. Educational and Psychological Measurement 1974; $34: 25-33$

27. Vinzi VE, Trinchera L, Amato S. PLS path modeling: from foundations to recent developments and open issues for model assessment and improvement. $1^{\text {st }}$ Edition, In Hand book of partial least squares: Springer: Berlin, Heidelberg, 2010

28. Fornell C, Larcker DF. Evaluating structural equation models with unobservable variables and measurement error. Journal of Marketing Research $1981 ; 18: 39-50$

29. Magner N, Welker RB, Campbell TL. Testing a model of cognitive budgetary participation processes in a latent variable structural equations' framework. Accounting and Business Research 1996; 27:41-50

30. Chin, Wynne W. "Commentary: Issues and Opinion on Structural Equation Modeling 1998: 7-8

31. Henseler J, Ringle CM, Sinkovics RR. The use of partial least squares path modeling in international marketing. In New challenges to international marketing 2009 Mar 6. Emerald Group Publishing Limited.

32. M. Tenenhaus, S. Amato, V. Esposito Vinzi, A global goodness-of-fit index for PLS structural equation modelling, in: Proceedings of the XLII SIS Scientific Meeting 2004; 14: 739-742

33. Ringle CM. Segmentation for path models and unobserved heterogeneity: The finite mixture partial least squares approach. University of Hamburg research paper on marketing and retailing 2006 Nov. Available at SSRN: https://ssrn.com/abstract=1586309or http://dx.doi.org/10.2139/ssrn.1586309.

34. Suriya Begum, M. Computing, Comparison of various techniques in IoT for health care system. International Journal of Computer Science and Mobile Computing 2016; 5:59-66

35. V.J.I.D. Bhatiasevi, An extended UTAUT model to explain the adoption of mobile banking. Information Development 2016; 322: 799-814

36. Suriya Begum V. Comparison of various techniques in IOT for healthcare system. International Journal of Computer Science and Mobile Computing. 2016; 5: 59-66

37. Alpay LL, Henkemans OB, Otten W, Rovekamp TAJM, Dumay ACM. E-health Applications and Services for Patient Empowerment: Directions for Best Practices in The Netherlands. Telemedicine and e-Health 2010; 16:787-91

38. Arsand E, Demiris G. User-centered methods for designing patient-centric self-help tools. Informatics for Health \& Social Care 2008; 33:158169

39. Keselman A, Logan R, Smith CA, Leroy G, Zeng-Treitler Q. Developing Informatics Tools and Strategies for Consumer-centered Health Communication. Journal of the American Medical Informatics Association 2008; 15:473-483

40. Bhatiasevi V. An extended UTAUT model to explain the adoption of mobile banking. Information Development 2016; 32:799-814 
41. Wang $X$. Using attitude functions, selfefficacy, and norms to predict attitudes and intentions to use mobile devices to access social media during sporting event attendance. Mobile Media \& Communication 2015; 3:75-90

42. Sun Y, Liu L, Peng X, Dong Y, Barnes SJ. Understanding Chinese users' continuance intention toward online social networks: an integrative theoretical model. Electronic Markets 2014; 24:57-66

43. Park J, Yang S, Lehto X. Adoption of mobile technologies for Chinese consumers. Journal of Electronic Commerce Research 2007; 8:3

44. Wills MJ, El-Gayar OF, Bennett D. Examining healthcare professionals' acceptance of electronic medical records using UTAUT. Issues in Information Systems 2008; 9:396-401

45. Moores TT. Towards an integrated model of IT acceptance in healthcare. Decision Support Systems 2012; 53:507-16

46. Wang X, White L, Chen X, Gao Y, Li H, Luo Y. An empirical study of wearable technology acceptance in healthcare. Industrial Management \& Data Systems 2015; 9: 1704-1723

47. Kalankesh L, Weatherall J, Ba-Dhfari T, Buchan IE, Brass A. Taming EHR data: using semantic similarity to reduce dimensionality. Medical Information for Patients 2013; 1:52-56

48. Aarts H, Verplanken B, Van Knippenberg A. Predicting behavior from actions in the past: Repeated decision making or a matter of habit? Journal of Applied Social Psychology 1998; 28:1355-74

49. Webb TL, Sheeran P, Luszczynska A. Planning to break unwanted habits: Habit strength moderates implementation intention effects on behavior change. British Journal of Social Psychology 2009; 48:507-23

50. Wang HY, Wang SH. Predicting mobile hotel reservation adoption: Insight from a perceived value standpoint. International Journal of Hospitality Management 2010; 29:598-608

51. Chang EC, Tseng YF. Research notes: E-store image, perceived value and perceived risk. Journal of Business Research 2013; 66:864-70

52. Soltani I, Gharbi JE. Determinants and consequences of the website perceived value. The Journal of Internet Banking and Commerce 1970; 13:1-3

53. Zhao L, Lu Y, Zhang L, Chau PY. Assessing the effects of service quality and justice on customer satisfaction and the continuance intention of mobile value-added services: An empirical test of a multidimensional model. Decision Support Systems 2012; 52:645-56

54. Kuo YF, Wu CM, Deng WJ. The relationships among service quality, perceived value, customer satisfaction, and post-purchase intention in mobile value-added services. Computers in Human Behavior 2009; 25:887-96

55. Venkatesh V, Bala H. Technology acceptance model 3 and a research agenda on interventions. Decision Sciences 2008; 39:273-315

56. Limayem M, Hirt SG, Cheung CM. How habit limits the predictive power of intention: The case of information systems continuance. MIS quarterly 2007:705-37

57. Kim SS, Malhotra NK. A longitudinal model of continued IS use: An integrative view of four mechanisms underlying postadoption phenomena. Management Science 2005; 51:741-55

58. Ratchford BT, Talukdar D, Lee MS. A model of consumer choice of the Internet as an information source. International Journal of Electronic Commerce 2001; 5:7-21

59. Kim HW, Chan HC, Gupta S. Value-based adoption of mobile internet: an empirical investigation. Decision Support Systems 2007; 43:111-26

60. Mallat N. Exploring consumer adoption of mobile payments - A qualitative study. The Journal of Strategic Information Systems 2007; 16:413-32

61. Dwivedi YK, Shareef MA, Simintiras AC, Lal B, Weerakkody V. A behavioral adoption model for services: A cross-country comparison of mobile health (m-health). Government Information Quarterly 2016; 33:174-87

62. El-Wajeeh M, Galal-Edeen GH, Mokhtar H. Cloud computing for mobile health: Opportunities and Challenges 2016;3: 09-14

63. Kossman SP, Scheidenhelm SL. Nurses' perceptions of the impact of electronic health records on work and patient outcomes. CIN: Computers, Informatics, Nursing 2008 1;26:69-77

64. Detmer WM, Friedman CP. Academic physicians' assessment of the effects of computers on health care. Annual Symposium on Computer Application in Medical Care 1994; 1: 558-62

65. Walter Z, Lopez MS. Physician acceptance of information technologies: Role of perceived threat to professional autonomy. Decision Support Systems 2008; 46:206-15 
66. Sarbaz M. Health information security. Fourth regional electronic health conference. Eastern Mediterranean 2004; 71:7-9

67. Hajavi A, Sarbaz M, Moradi N. Medical Records 3\&4. 1st Edition, Jahanrayane: Tehran, 2003

68. Hillestad R, Bigelow J, Bower A, Girosi F, Meili R, Scoville R, Taylor R. Can electronic medical record systems transform health care? Potential health benefits, savings, and costs. Health affairs 2005; 24:1103-17

69. Piry Z. Determinants of the acceptance and development of HER implementation. Fourth reginal electronic health conference. Eastern Mediterranean 2004; 15: 7-9

70. Safdari R, Rorabi M. Electronic Health Records. $1^{\text {st }}$ Edition, Behineh: Teharan, 2005

71. Neumann $M$, Edelhäuser $F$, Tauschel $D$, Fischer MR, Wirtz M, Woopen C, Haramati A, Scheffer C. Empathy decline and its reasons: a systematic review of studies with medical students and residents. Academic Medicine 2011; 86:996-1009
72. Lynch DJ, McGrady AV, Nagel RW, Wahl EF. The patient-physician relationship and medical utilization. Primary care companion to the Journal of Clinical Psychiatry 2007; 9:266

73. Hsu J, Huang J, Fung V, Robertson N, Jimison H, Frankel R. Health information technology and physician-patient interactions: impact of computers on communication during outpatient primary care visits. Journal of the American Medical Informatics Association 2005; 12:474-80

74. Abdekhoda M, Ahmadi M, Gohari M, Noruzi A. The effects of organizational contextual factors on physicians' attitude toward adoption of Electronic Medical Records. Journal of Biomedical Informatics 2015; 53:174-9 